\title{
Aggregate Volatility Risk and Momentum Returns
}

by Efdal Ulas Misirli

\author{
Submitted in Partial Fulfillment \\ of the \\ Requirements for the Degree \\ Doctor of Philosophy
}

Supervised by

Professor John B. Long

William E. Simon Graduate School of Business Administration

University of Rochester

Rochester, New York

2012 


\section{Dedication}

I dedicate this dissertation to my parents, Zulal Misirli and Tevfik Misirli. 


\section{Curriculum Vitae}

Efdal Ulas Misirli was born in Istanbul, Turkey on September 11, 1978. He attended Bogazici University from 1997 to 2002, and graduated with a Bachelor of Arts degree in Management. He subsequently worked for PricewaterhouseCoopers as an auditor. He returned to Bogazici University in 2003 and began graduate studies in Economics. He received a Master of Arts degree in Economics in 2006. He came to University of Rochester in Summer 2006, and began his graduate studies in Finance. He received graduate fellowship at Simon School from 2006 to 2010. He pursued his research in asset pricing under the direction of Professor

John B. Long, and received the Master of Science in Business Administration from the University of Rochester in 2009. 


\section{Acknowledgements}

I thank my committee members John Long (advisor), Robert Novy-Marx and Jerry Warner for their helpful comments and suggestions. I also thank Tim Johnson, Ron Kaniel, Robert Ready, Bill Schwert, Wei Yang, seminar participants at University of Alberta, University of Connecticut, Koc University, London School of Economics Alternative Investments Research Conference, Ozyegin University, University of Rochester as well as Ph.D. students in Simon School, in particular, Egor Matveyev, Justin Vitanza and Casey Zak. I thank Ken French for providing data via his website. Finally, I thank my friends in Rochester for their sincere friendship and support throughout my Ph.D. program. 


\begin{abstract}
Momentum profits are generated by winners' exposure to aggregate volatility risk. A proxy for aggregate volatility shock (AVS) which comes from an EGARCH $(1,1)$ model of monthly market excess returns is a priced risk factor in cross-sectional regressions and commands a negative risk premium. Winners have negative AVS loadings thereby earning higher average returns than do losers. Event time analyses reveal important insights about the temporary nature of momentum profits. For example, I find that winners have lower AVS loadings than do losers over the first 6 months of the holding period and that the difference in loadings becomes mostly insignicant thereafter. Another event-time study shows that the profitability of momentum strategies after up-market states can also be attributed to the difference in aggregate volatility risk. I explain the negative AVS loadings of winners with a real option argument. Over the evaluation period winner firms develop growth options and their market values become sensitive to aggregate demand conditions. AVS is a negative demand shock that causes investment cuts and downward revisions in future earnings. The decline in investment growth and thereby the loss in market value is more pronounced for winners. Moreover, the reversal of momentum returns one year after portfolio formation is partly explained by the negative cross-sectional relation between real investment and average returns. Additional robustness checks and comparison with conditional CAPM suggest that the ICAPM with aggregate volatility risk is an important multifactor model that accounts for the cross-sectional return variation of momentum stocks.
\end{abstract}




\section{Contents}

1 Introduction 1

2 Empirical Framework and Data 5

2.1 Literature Review and the Multifactor Model . . . . . . . . . 5

2.2 ICAPM Innovations . . . . . . . . . . . . . . . 8

2.2.1 VAR Model and News about Future Market Returns . . . 8

2.2.2 EGARCH Model and News about Future Market Volatility 9

2.3 Data . . . . . . . . . . . . . . . 11

3 Descriptive Statistics and Asset Pricing Tests 13

3.1 Descriptive Statistics . . . . . . . . . . . . . 13

3.2 Fama-MacBeth (1973) Method .............. 15

4 Event Time Analysis $\mathbf{2 5}$

4.1 Research Design . . . . . . . . . . . . . . . 25

4.2 Results and Discussion . . . . . . . . . . . 26

4.3 Reversal of AVS loadings over the evaluation period . . . . . . . . 30

4.4 Further Evidence on Market States and Momentum . . . . . . . 32

5 Evidence on Corporate Investment and Momentum Returns $\quad 34$

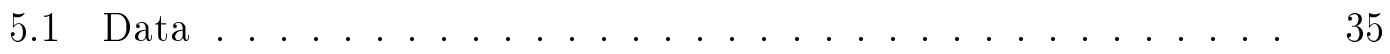

5.2 The Impact of AVS on Corporate Investment . . . . . . . . . 35

5.3 The Impact of Corporate Investment on Subsequent Returns . . . 38

6 Comparison with Conditional CAPM 40

6.1 Testing Procedure . . . . . . . . . . . . . . 40

6.2 Results and Discussion . . . . . . . . . . . . . . 42

7 Further Evidence on Momentum Anomaly 44

7.1 Information Uncertainty or Existence of Growth Options . . . . . 44

7.2 ICAPM with VIX Innovations . . . . . . . . . . . 45

8 Conclusion $\quad 48$ 


\section{List of Tables}

Table 1: Aggregate Volatility Shock

Table 2: Fama-MacBeth (1973) Method: ICAPM with EGARCH $(1,1)$ model

Table 3: Alternative Momentum Strategies

Table 4: Fama-MacBeth (1973) Method:

Four Factor Model (Rm-Rf, SMB, HML, AVS)

Table 5: Time Series Evolution of Aggregate

Volatility Shock (AVS) Loadings

Table 6: Event Time Analysis: Market States and Holding Period Statistics

Table 7: The Impact of Volatility Shock on

Abnormal Investment Growth

Table 8: The Impact of Investment on

Subsequent Returns

Table 9: Conditional CAPM

Table 10: Fama-MacBeth (1973) Method with

Conditional Momentum Strategies

Table 11: ICAPM with VIX Innovations 


\section{List of Figures}

Figure 1: Aggregate Volatility Shock

Figure 2: AVS Loadings from Event Time

Regressions - Full Sample

Figure 3: AVS Loadings from Event Time

Regressions - Subperiod Evidence

Figure 4: Event-Time Analysis:

Two Alternative Specifications 


\section{List of Abbreviations}

$\begin{array}{ll}\text { AIG: } & \text { Abnormal Investment Growth } \\ \text { AVS: } & \text { Aggregate Volatility Shock } \\ \text { CAPM: } & \text { Capital Asset Pricing Model } \\ \text { DEF: } & \text { Default Premium } \\ \text { DIV: } & \text { Dividend Yield } \\ \text { EGARCH: } & \text { Exponential Generalized Autoregressive Conditional } \\ & \text { Heteroskedastic } \\ \text { GLS: } & \text { Generalized Least Squares } \\ \text { GMM-HAC: } & \text { Generalized Method of Moments-Heteroskedasticity and } \\ & \text { Autocorrelation Consistent } \\ \text { HML: } & \text { High-Minus-Low, Book-to-Market Factor of Ken French } \\ \text { ICAPM: } & \text { Intertemporal Capital Asset Pricing Model } \\ \text { inv: } & \text { Corporate Investment } \\ \text { M/B: } & \text { Market-to-Book Ratio } \\ \text { OLS: } & \text { Ordinary Least Squares } \\ \text { ROA: } & \text { Return on Assets } \\ \text { RF: } & \text { Riskfree Rate } \\ \text { Rm-Rf: } & \text { Market Excess Return } \\ \text { SMB: } & \text { Small-Minus-Big, Size Factor of Ken French } \\ \text { TERM: } & \text { Term Premium } \\ \text { UMD: } & \text { Up-Minus-Down, Momentum Factor of Ken French } \\ \text { VAR: } & \text { Vector Autoregression } \\ \text { WML: } & \text { Winner-Minus-Loser, Momentum Portfolio }\end{array}$




\section{Introduction}

One of the main goals of empirical asset pricing literature is to identify reasonable risk factors that determine the cross-sectional variation in expected returns. In this regard, Merton's (1973) ICAPM and subsequent extensions by Campbell (1993, 1996) and Chen (2003) provide theoretical guidance to empiricists who want to explain cross-sectional return variation of assets with innovations in state variables that are of concern to investors. Two important papers that follow this track include Petkova (2006) and Ang, Hodrick, Xing and Zhang (2006). Petkova finds that innovation in state variables that forecast future market returns explain the cross-section of expected returns on 25 size and book-to-market portfolios. Similarly, Ang et al show that stocks with high exposure to the innovation in aggregate volatility have low expected returns. In this paper I aim to contribute to this track by looking at the importance of aggregate volatility risk in the momentum cross-section.

I measure the volatility risk of a momentum portfolio as the sensitivity of its excess return to innovation in market volatility. I run an EGARCH $(1,1)$ model for monthly market excess returns in order to generate my proxy for aggregate volatility shock (AVS). I propose a multifactor model that includes AVS together with market excess return and innovations in predictive variables as its risk factors. The predictive variables are dividend yield, default premium, term premium and risk-free rate. This empirical specification helps me shed light on some issues that puzzle the proponents of a risk-based explanation for the momentum anomaly.

The first success comes from the Fama-MacBeth (1973) procedure. AVS is a priced risk factor for momentum portfolios and commands a negative risk premium. Winners have negative AVS loadings and earn higher average returns 
than do losers. This evidence is consistent with the predictions of Chen's (2003) ICAPM with time varying market volatilities. A positive volatility shock signals uncertainty about future market volatility and triggers a precautionary savings motive for investors. The winner portfolio does not pay off when investors reduce their consumption; therefore, such stocks are less desirable and investors demand higher expected returns to hold them. The AVS loadings of momentum stocks increase monotonically as I move from the winner portfolio to the loser portfolio. In short, the risk pattern coincides with the average return pattern across the momentum cross-section.

The second success comes from event time regressions in the manner of Ball and Kothari (1989). For each month in event time relative to the portfolio formation month, I estimate the sensitivity of momentum portfolios to aggregate volatility risk with my empirical ICAPM specification. Winners have lower AVS loadings than losers over the first 6 months of the holding period of the momentum strategy and the difference in AVS loadings becomes mostly insignificant thereafter. Consequently, the cross-sectional dispersion of AVS loadings after portfolio formation is roughly consistent with the temporary nature of momentum profits.

In a similar event time analysis Jegadeesh and Titman (1993) pick CAPM as their empirical model and provide evidence that time varying risk does not explain the profitability of their momentum strategy. Moreover, in Jegadeesh and Titman (2001) they advocate for Daniel et al.'s (1998) delayed overreaction model as the main driver of short-term return continuation. I argue, however, that time varying risk can still be the source of momentum profits. An intertemporal CAPM representing the hedging demands of investors can be an alternative benchmark to the traditional CAPM to evaluate the performance of risk-based explanations for the profitability of momentum strategies. 
In a recent study Cooper, Gutierrez and Hameed (2004) uncover an important event time result about momentum profits: they depend on market states. For example, investors observe such profits only when the two-year-lagged market return is nonnegative. Cooper et al. explain this result with overreaction theory. They argue that investor overconfidence is greater after market gains. The increase in overconfidence furthers investor overreaction and leads to higher momentum payoffs. I find, however, that the profitability of this conditional momentum strategy can be attributed to the difference in sensitivity to innovation in aggregate volatility. Winners have lower AVS loadings than losers after an up-market state. The zero return on the WML portfolio after a down-market state is also consistent with its exposure to volatility risk. The winner portfolio and the loser portfolio have the same AVS loadings when such a state occurs.

The AVS loadings from time series regressions introduce ICAPM as a potential candidate for explaining the momentum anomaly. Nevertheless, a risk-based explanation for the momentum anomaly should reveal the economic meaning of these loadings and explain their dispersion across the momentum cross-section. To achieve this goal, I use a real option argument.

Mechanically, the market-to-book ratios of winners increase during the evaluation period, so I assume that winners develop growth options and their market values become more sensitive to aggregate demand conditions. Chen's (2003) ICAPM predicts that a positive aggregate volatility shock leads to an increase in precautionary savings and a decline in product demand. In their real option model Carlson, Fisher and Giammarino (2004, 2006) show that when product demand falls, firms with valuable growth options do not exercise their options; hence their market values decline. Motivated by the predictions of these two papers, I argue that winner firms cancel their valuable investment projects as the market 
uncertainty is rising and the economic outlook is getting worse. To support this argument, I create an abnormal investment proxy for momentum firms and compute its sensitivity to volatility news. Specifically, a ten percent increase in AVS leads to a two percent drop in the investment activity of winners relative to their preevaluation period capital spending. As winners slow down their investment growth, investors would revise downward their expectations about winners' future earnings prospects. As a result, winners' returns covary negatively with the innovation in aggregate volatility.

Finally, a risk-based explanation should clarify the temporary nature of momentum profits. During the first year of the holding period, the winner portfolio earns higher average returns than does the loser portfolio; afterwards, the average return pattern reverses. I explain this fact by bridging two results in the asset pricing literature.

The first result comes from the momentum literature. In two recent papers, Liu and Zhang (2008) and Chen, Novy-Marx and Zhang (2011) uncover that winners invest more than losers from the beginning of the ranking period to the end of the first year of the holding period. The second result comes from several studies on the cross-sectional determinants of expected returns (such as Fama and French [2006], Cooper, Gulen and Schill [2008], Anderson and Garcia-Feijoo [2006], Titman, Wei and Xie [2004]), which document a negative relation between investment and subsequent returns. Combining these two lines of research, I show that the annual capital spending that winner firms initiate in the middle of the ranking period forecasts significant declines in their subsequent returns.

The remainder of this paper is as follows: Section 2 motivates the multifactor model that I use throughout the paper. Section 3 reports the results of FamaMacBeth (1973) procedure and examines the ability of aggregate volatility shock 
to price the momentum cross-section. Section 4 reports the results of event time regressions and presents the evolution of AVS loadings and momentum profits in preranking and postranking months. Section 5 shows how volatility news affects the capital spending of different momentum firms and investigates the relation between investment and reversal of momentum returns. Section 6 compares and contrasts ICAPM with the conditional CAPM specification of Petkova and Zhang (2005). Section 7 provides additional evidence on the importance of aggregate volatility news for growth option firms. Section 8 concludes.

\section{Empirical Framework and Data}

\subsection{Literature Review and the Multifactor Model}

The goal of this paper is to provide a risk-based explanation for the momentum anomaly; therefore, the first step is to define an empirical model. I follow the consumption based asset pricing literature and use ICAPM to specify the risk factors in the pricing kernel.

Aggregate consumption becomes unsuccessful in asset pricing tests and finance scholars question its information content because investors are likely to have a different consumption pattern than that of regular citizens. In addition, since aggregate consumption data are only available at a quarterly frequency, econometricians lose statistical power when they use consumption data in their analysis. The ICAPM of Merton (1973) helps the econometrician to mitigate the problems of consumption data by decomposing the consumption innovation into components that are of concern to investors. These components are the market return and innovations in state variables that describe the time variation in the invest- 
ment opportunity set. The extensions by Campbell (1996) and Chen (2003) take one further step and suggest proxies for these innovations.

In Campbell's (1996) study, relevant risk factors are market excess return and innovations in variables that predict market excess returns. Examples for these state variables are the aggregate dividend yield (DIV), default premium (DEF), term premium (TERM) and the one-month Treasury bill yield (RF). Recently, Petkova (2006) finds that a multifactor model that includes innovations in these variables explains the cross section of average returns of 25 size/book-to-market portfolios.

Chen (2003) extends Campbell's work to an environment where fluctuations in market volatility cause a precautionary savings motive for the ICAPM investor and thereby a decline in his consumption. Aggregate volatility shock (AVS) emerges as an additional risk factor in the pricing kernel and stocks that covary positively with this shock earn low average returns because such stocks give the investor an opportunity to hedge against consumption risk. Alternatively, stocks that have negative covariance with AVS have high expected returns because they do not pay off when the marginal utility of the investor is high. Chen uses a GARCH $(1,1)$ model to generate a proxy for this new risk factor. Ang et al (2006) follow Chen's study and suggest changes in VIX as an alternative proxy for the volatility shock. They also find that a multifactor model that augments the mimicking portfolio of this proxy (FVIX) with Fama-French (1996) factors performs well in crosssectional regressions.

In this paper I refer to Chen's version of ICAPM to define my multifactor model. AVS features as the main risk factor for the momentum cross-section. I also control for innovations in predictive variables in order to be consistent with ICAPM and to mitigate the concern that they do not contain the information in 
AVS. Unlike Chen, I estimate an EGARCH $(1,1)$ model for monthly excess market returns to form my volatility shock measure because EGARCH models allow for asymmetric effects between positive and negative market returns. In short, I study the pricing ability of the following unconditional model:

$$
E\left(r_{i t}-r_{f t}\right)=\left(\gamma_{R m-R f}\right)\left(\beta_{i, R m-R f}\right)+\sum_{K}\left(\gamma_{u^{K}}\right)\left(\beta_{i, u^{K}}\right)+\left(\gamma_{A V S}\right)\left(\beta_{i, A V S}\right)
$$

where $\gamma_{R m-R f}, \gamma_{u^{K}}$ and $\gamma_{A V S}$ are the prices of risk for the market excess return $(R m-R f)$, the innovation in state variable $K \in\{D I V, D E F, T E R M, R F\}$, and the aggregate volatility shock $(A V S)$, respectively.

I hesitate to use FVIX for two reasons. First, EGARCH shock has longer time series than does FVIX. Jegadeesh and Titman (1993) document that momentum profits exist since 1941. The EGARCH model enables me to run asset pricing tests over the full sample period 1941-2009 and over subperiods. On the other hand, the series for FVIX starts in 1986 and would make me focus on a shorter time period. Second, the EGARCH model captures uncertainty at longer horizons. Whaley (2000) notes that VIX has a thirty calendar day horizon which is very short for the real investment plans of corporations. Liu and Zhang (2008) and Chen, NovyMarx and Zhang (2011) show that corporate investment choices differ among momentum firms. Since I study the impact of volatility shock on momentum firms' capital expenditure, I use EGARCH shock as my proxy for innovation in market volatility.

The three-factor model of Fama and French $(1993,1996)$ is the most successful multifactor model in asset pricing, but it does not explain the momentum anomaly. The loadings on Rm-Rf, SMB and HML do not align with the average returns of the momentum portfolios, and this failure is widely used as evidence 
against risk-based explanations. Fama and French argue that SMB and HML are mimicking portfolios for two state variables that can cause special hedging concern to ICAPM investors. Petkova (2006) reveals the identities of these state variables and shows that HML proxies for the innovation in term premium and SMB proxies for innovation in default spread. In this paper, I argue that enriching the ICAPM with innovation in aggregate volatility helps explain the cross-sectional return variation of momentum portfolios and provides a new direction for the risk-based approach.

\subsection{ICAPM Innovations}

\subsubsection{VAR Model and News about Future Market Returns}

As in Petkova (2006), the set of state variables that describe future investment opportunities consists of the dividend yield (DIV), default premium (DEF), term premium (TERM) and the one month Treasury bill rate $(\mathrm{RF}) .{ }^{1}$ By adding the excess return on the market $\mathrm{Rm}-\mathrm{Rf}$ to the set of state variables, I specify the following first-order VAR:

$$
\left[\begin{array}{c}
R_{M, t}-R_{f, t} \\
D I V_{t} \\
D E F_{t} \\
T E R M_{t} \\
R F_{t+1}
\end{array}\right]=c+A \cdot\left[\begin{array}{c}
R_{M, t-1}-R_{f, t-1} \\
D I V_{t-1} \\
D E F_{t-1} \\
T E R M_{t-1} \\
R F_{t}
\end{array}\right]+\left[\begin{array}{c}
u_{t}^{R_{M}-R_{f}} \\
u_{t}^{D I V} \\
u_{t}^{D E F} \\
u_{t}^{T E R M} \\
u_{t+1}^{R F}
\end{array}\right]
$$

where $u_{t}$ denotes the vector of innovations in state variables. Campbell (1996)

\footnotetext{
${ }^{1}$ The papers stimulating the use of these variables are Fama and French (1988) for DIV, Fama and Schwert (1977) for RF and Fama and French (1989) for DEF and TERM.
} 
shows that he can write the news about future market returns as a linear combination of VAR residuals, so these shocks become reasonable candidates for risk factors within ICAPM. Similar to Petkova (2006), I scale the VAR residuals so that they have the same variance as the innovation in the market excess return, but unlike Petkova I do not orthogonalize these residuals because there is no theoretical justification for the order of orthogonalization. It is also worth mentioning that the results in this paper do not change when I use orthogonal shocks.

In short, the VAR shocks proxy for news about future investment opportunities, and an empirical study that uses ICAPM should employ them as risk factors. Therefore, I include them in my multifactor model along with the aggregate volatility shock that I create with an EGARCH $(1,1)$ model for monthly market excess returns.

\subsubsection{EGARCH Model and News about Future Market Volatility}

I assume the following mean and variance equations for the excess return on the market.

Mean Equation: $r_{m, t}-r_{f, t}=c_{0}+c_{1} \cdot D I V_{t-1}+c_{2} \cdot D E F_{t-1}+c_{3} \cdot T E R M_{t-1}+$ $c_{4} \cdot R F_{t}+\varepsilon_{t}$

Variance Equation: $\ln \sigma_{t+1}^{2}=(1-\Delta) \alpha+\Delta \cdot \ln \sigma_{t}^{2}+\theta \cdot \frac{\varepsilon_{t}}{\sigma_{t}}+\gamma \cdot\left(\left|\frac{\varepsilon_{t}}{\sigma_{t}}\right|-\sqrt{\frac{2}{\pi}}\right)$

Then we can express revisions in expectations about future ( $s$-month ahead) market volatility as follows: 
$\left(E_{t+1}-E_{t}\right) \sigma_{t+1+s}^{2}=\Gamma_{s}\left\{\exp \left[\Delta^{s-1} \cdot g\left(\frac{\varepsilon_{t+1}}{\sigma_{t+1}}\right)\right]-E_{t}\left(\exp \left[\Delta^{s-1} \cdot g\left(\frac{\varepsilon_{t+1}}{\sigma_{t+1}}\right)\right]\right)\right\}$

where $g\left(\frac{\varepsilon_{t+1}}{\sigma_{t+1}}\right)=\theta \cdot \frac{\varepsilon_{t+1}}{\sigma_{t+1}}+\gamma \cdot\left(\left|\frac{\varepsilon_{t+1}}{\sigma_{t+1}}\right|-\sqrt{\frac{2}{\pi}}\right)$ is the weighted innovation of the EGARCH $(1,1)$ model,

$\Gamma_{s}=(\exp [\alpha])^{1-\Delta^{s}} \cdot\left(\sigma_{t+1}^{2}\right)^{\Delta^{s}} \cdot \prod_{m=1}^{s-1} \kappa_{m}$ is a positive constant that depends on $s$ and

$\kappa_{m}=E_{t}\left(\exp \left[\Delta^{m-1} \cdot g\left(\frac{\varepsilon_{t+1}}{\sigma_{t+1}}\right)\right]\right)$. I benefit from the Appendix of Cao and Tsay (1992) to derive these results.

Equation (3) tells us that changes in the forecasts of future market volatilities are positively related to the innovation in aggregate volatility, $g\left(\frac{\varepsilon_{t+1}}{\sigma_{t+1}}\right)$. A positive innovation triggers a precautionary savings motive for the ICAPM investor. As a result, he reduces his consumption and his marginal utility rises. Stocks that pay off in this unfavorable consumption state become desirable for him and he would demand lower expected returns for such securities. In short, Chen's (2003) model implies that this innovation, which I denote as $A V S$, commands a negative risk premium and stocks that load highly on this innovation earn low average returns.

Once I create all of the ICAPM innovations, I can use them in Fama-MacBeth method and compute their risk premia. I perform this task after I describe the data sources and give some preliminary statistics. 


\subsection{Data}

In this paper, I use monthly data from May 1953 to December 2009. The start of the test period is determined by the availability of data on term premium. I also investigate the pricing ability of a four-factor model that augments the EGARCH shock with the three factors of Fama and French (1996). In that empirical work the sample covers the period January 1941-December 2009. Data on stock returns and risk factors come from different sources.

The test assets are 10 momentum portfolios, 12 industry portfolios, a one year government bond, a ten year government bond and the market portfolio. I form momentum portfolios by using individual stock return data that I download from CRSP. The data files for market excess return (Rm-Rf), risk free rate $(\mathrm{RF})$ and industry portfolios come from Professor Ken French's website. ${ }^{2}$ The source for the time series of government bonds is WRDS.

The main test assets are 10 overlapping momentum portfolios that I form by following the procedure in Jegadeesh and Titman (1993). My sample consists of all stocks in the CRSP database over the years 1953-2009. I exclude all stocks whose price is less than $\$ 1$ at the beginning of the holding period. At the end of each month (t), I rank the stocks in my sample with respect to their prior five month returns from month (t-6) to month (t-1) and then group them into 10 equal-weighted portfolios according to these ranks. Similar to Fama and French (1996) and Liu and Zhang (2008), I skip one month between the end of the ranking period and the start of the holding period. After forming the portfolios, I hold them for six months from month $(\mathrm{t}+1)$ to month $(\mathrm{t}+6)$. I construct momentum portfolio returns by weighting each monthly cohort equally.

\footnotetext{
${ }^{2}$ http://mba.tuck.dartmouth.edu/pages/faculty/ken.french/data_library.html
} 
Lewellen, Nagel and Shanken (2010) argue that the three factor model of Fama and French $(1993,1996)$ explains most of the time series variation of portfolios sorted by size and book-to-market; therefore, any macroeconomic factor that is slightly correlated with SMB or HML, but not with the small residuals of the three-factor model, can explain the cross-sectional variation in these portfolios. To mitigate this problem, Lewellen et al suggest augmenting size and book-to-market portfolios with industry portfolios or government bonds. They also recommend running GLS regressions and including a factor portfolio among test assets. The strong structure problem is also valid for momentum portfolios because Carhart's (1997) four factor model explains almost all of the time series variation in momentum portfolios. In order to respond to the critique of Lewellen et al, I add industry portfolios, government bonds and the market portfolio to the set of test assets.

The risk factors in my multifactor model are market excess return, innovation in variables that forecast market returns (VAR shocks) and innovation in aggregate volatility (EGARCH shock). The predictive variables are dividend yield, default premium, term premium and one month Treasury bill rate. Dividend yield is the ratio of the sum of monthly dividends paid on the CRSP value weighted market portfolio over the previous year to the level of the portfolio. Default premium is the yield spread between Baa bonds and Aaa bonds. Term premium is the yield spread between 10 year government bond and 3 month Treasury bill. I follow Fama and French (1988) to construct the dividend yield series and I download the interest rate data from the website of the Federal Reserve System. 


\section{Descriptive Statistics and Asset Pricing Tests}

In this section I construct an aggregate volatility shock series for the time period May 1953 - December 2009 and provide evidence on the ability of this shock to price the momentum cross-section. I start the section with the descriptive statistics of the aggregate volatility shock (AVS) that I compute with an EGARCH $(1,1)$ model for excess market returns. Next, I present the output of the Fama-MacBeth (1973) method over the full sample period. I use two alternative empirical models in cross-sectional regressions. The first model is the multifactor model that I propose in section 2. The factors are market excess return, innovations in predictive variables and AVS. The second empirical model is a four-factor model that I formulate by augmenting the three factors of Fama and French with AVS. In both empirical specifications, AVS emerges as an important factor that explains the cross-sectional variation in average returns on momentum portfolios. Consistent with ICAPM, AVS commands a negative risk premium. In addition, recent winners have lower loadings on this innovation and thereby earn higher average returns than do recent losers. I also estimate AVS loadings in subperiods to show that results hold in different sample periods. Finally, I look at the robustness of results to alternative momentum strategies.

\subsection{Descriptive Statistics}

Table 1 presents the parameter estimates of the EGARCH $(1,1)$ model as well as the descriptive statistics of the aggregate volatility shock that I generate with this time series model. The estimates of parameters in the mean equation and the variance equation in Panel A are in line with the estimates found in ear- 
lier studies. For example, the aggregate dividend yield and the default premium predict positive excess market returns and the one month T-bill yield forecasts negative market returns. In addition, the asymmetry term in the variance equation, $\theta$, is negative and highly significant; a negative standardized shock leads to a higher conditional variance next period than does a positive shock of the same size. More importantly, the EGARCH model enables me to generate my proxy for AVS, the weighted innovation $g\left(\frac{\varepsilon_{t}}{\sigma_{t}}\right)$, by using the parameter estimates and the standardized residual in the following formula: $g\left(\frac{\varepsilon_{t}}{\sigma_{t}}\right)=\theta \cdot \frac{\varepsilon_{t}}{\sigma_{t}}+\gamma \cdot\left(\left|\frac{\varepsilon_{t}}{\sigma_{t}}\right|-\sqrt{\frac{2}{\pi}}\right)$.

Panel B of Table 1 displays the descriptive statistics of the weighted innovation. Its mean is not significantly different from zero and the p-value associated with the Ljung and Box (1978) Q-statistic confirms that this innovation has no significant serial correlation. Next, I report the correlation coefficients of this innovation with the excess return on the market and three alternative measures for the volatility shock.

The weighted innovation $g\left(\frac{\varepsilon_{t}}{\sigma_{t}}\right)$ has a negative and significant contemporaneous relation with excess market return. French, Schwert and Stambaugh (1987) point out that a positive surprise in volatility leads to upward revisions in predicted volatility of future time periods. If the market risk premium is positively related to predicted volatility, the discount rates for future cash flows will rise. If cash flows are unaffected by this volatility news, higher discount rates in future periods cause negative stock market return in the current period. French et al run an ARIMA model to construct a proxy for AVS and find evidence in favor of this argument by using their proxy. The negative correlation of -0.80 between excess market return and the weighted innovation in table 1 is also in line with this argument. Interestingly, the weighted innovation also has a high correlation of 0.50 with French et al's proxy $\sigma_{m, t}^{2 u}$. Two other measures for AVS are the unpredicted 
component of aggregate volatility from a $\operatorname{GARCH}(1,1)$ model $\left(\varepsilon_{t}^{2}-\sigma_{t}^{2}\right)$ of monthly excess returns and the monthly changes in the level of VIX $\left(\Delta_{m} V I X\right)$. The weighted innovation of the EGARCH model is also highly correlated with these two proxies. Figure 1 plots the weighted innovation at a monthly frequency over my sample period (May 1953-December 2009). The three largest spikes in AVS occur when the stock market has its most negative returns in my sample: the market crash in 1987, the LTCM crisis in 1998 and the financial meltdown in 2008.

Finally, I regress AVS on Carhart's (1997) four factor model to test whether the momentum factor UMD proxies for innovation in aggregate volatility. The regression result in Panel B of Table 1 supports my hypothesis: UMD covaries negatively and significantly with AVS. In similar regressions, Petkova (2006) shows that SMB and HML proxy for the innovations in future investment opportunities. I contribute to her study by revealing the identity of the ICAPM shock that UMD represents. This result is encouraging because it helps me to interpret the four-factor model's success in explaining the cross-sectional return variation of momentum portfolios in terms of ICAPM. In the next subsection I show that the multifactor model that I propose in this paper prices the momentum cross-section as well.

\subsection{Fama-MacBeth (1973) Method}

After I create all innovations, I can evaluate their pricing performance by using the cross-sectional model in equation (1). The risk factors are market excess return (Rm-Rf), innovations in dividend yield $\left(u^{D I V}\right)$, default premium $\left(u^{D E F}\right)$, term premium $\left(u^{T E R M}\right)$, risk free rate $\left(u^{R F}\right)$ and the aggregate volatility shock (AVS). 
I use the Fama-MacBeth (1973) procedure in order to estimate the risk premium associated with each factor. Table 2 displays two sets of statistics for three sample periods. I estimate the first set of test statistics with cross-sectional regressions and the second set with time series regressions. There are three test periods, namely the full sample period (May-1953-December 2009) and two subperiods: May 1953-August 1981 and September 1981-December 2009. Each panel of Table 2 reports the statistics that come from one of these test periods. I employ 25 test assets: 10 equally-weighted momentum portfolios, 12 equally weighted industry portfolios, a long-term government bond, a short-term government bond and the market portfolio.

The cross-sectional test statistics are risk premium estimates, their corresponding Fama-MacBeth and Shanken (1992) t-statistics and two goodness-of-fit measures. Shanken t-statistics correct the standard errors of risk premium estimates for the fact that the factor loadings are estimated in the time series regression. The first goodness-of-fit measure is the OLS $R^{2}$ that is proposed by Jagannathan and Wang (1996) and subsequently used by many empirical studies, e.g., Lettau and Ludvigson (2001) and Petkova (2006). Lewellen, Nagel and Shanken (2010) question the performance of this metric when the test assets have strong factor structure. This applies to momentum portfolios as well as size and book-to-market portfolios. Therefore, I follow Lewellen et al. and report a second goodness-of-fit measure (GLS $R^{2}$ ) which is less severely affected by this problem.

The time series test statistics are the AVS loadings of 10 momentum portfolios and the p-values from two Wald tests. The first test, $H_{0}: \beta_{A V S}^{m o m}=0$, questions whether AVS loadings are jointly significant and the second test, $H_{0}: \beta_{A V S}^{W}=$ $\beta_{A V S}^{L}$, questions whether the winner portfolio and the loser portfolio have the same exposure to aggregate volatility risk. I estimate these statistics by running 
a system GMM that corrects for heteroscedasticity and autocorrelation up to 12 lags.

Panel A of table 2 covers the full sample period from May 1953 to December 2009. The multifactor model accomplishes several tasks. First, consistent with the ICAPM, aggregate volatility shock (AVS) commands a negative risk premium. The estimate of $-10.98 \%$ is highly significant, even after Shanken's (1992) correction. The AVS loading of the winner portfolio is $-4.96 \%$ and it is highly significant. Chen's ICAPM predicts that a positive volatility shock causes an increase in precautionary savings. Winner returns covary negatively with this unfavorable consumption state; therefore, investors demand higher expected returns to hold winner stocks. In addition, the AVS loadings increase monotonically from the winner portfolio to the loser portfolio and I can reject the null hypothesis that winners and losers have the same sensitivity to volatility news. In short, the crosssectional dispersion in average momentum returns is in line with the dispersion in aggregate volatility risk.

Second, the multifactor model achieves high OLS $R^{2}(87 \%)$ despite the fact that I expand the test assets beyond momentum portfolios. Average market excess return over this period is $0.53 \%$ and the estimated market risk premium of $0.63 \%$ is not significantly different from its historical average. Moreover, I cannot reject the null hypothesis that intercept term of the cross-sectional regression is zero. Hence, the equilibrium model in equation (1) seems to be a good candidate for the cross-section of asset returns.

Third, as shown in Panel B and C of table 2, Fama-MacBeth (1973) results hold in subsamples. Innovation in aggregate volatility has a negative price of risk, and winners' exposure to aggregate volatility risk differs significantly from losers' exposure in both subperiods. Winners covary negatively with AVS whereas 
losers have insignificant loadings. As a result, I argue that momentum profits are compensation for aggregate volatility risk and investors demand higher returns on winners because they are risky.

Fourth, the results of the Fama-MacBeth method hold when I follow alternative momentum strategies $(\mathrm{J} / 1 / \mathrm{K})$ and construct portfolios that differ in their sorting period J and holding period K. For each strategy I estimate the factor loading of the Winner-Minus-Loser (WML) portfolio on innovation in aggregate volatility as well as the risk premium associated with this innovation. Table 3 displays the results. In all strategies, the WML portfolio covaries negatively with the aggregate volatility shock and the loadings are all significant. Likewise, innovation in aggregate volatility commands a negative and significant risk premium in all strategies. In conclusion, the findings in Table 2 are not special to the $(6 / 1 / 6)$ strategy.

AVS features as the main risk factor for the momentum cross-section and the exposures of momentum portfolios to AVS have a distinctive pattern. Winners have negative and significant loadings whereas losers have insignificant loadings. I argue that this pattern results from the way investors value momentum firms. The value of a firm is the sum of its assets-in-place and its growth options. Mechanically, the market-to-book ratios of winners increase during the evaluation period (months -5 through -1 ), so I can assume that they develop growth options and their market values become more sensitive to the news about future demand associated with these options. ${ }^{3}$ A positive volatility shock is a negative demand shock; as a result, winners cancel their investments and the values of their growth options drop significantly. This investment cut would cause a downward revision

\footnotetext{
${ }^{3}$ Sagi and Seasholes (2007) use this argument and explain momentum profits with real option theory. However, they did not propose a systematic risk factor that prices the momentum crosssection.
} 
in expectations about future earnings and thereby a negative covariance between winner returns and AVS. Growth options constitute a lower fraction of the market value of losers; therefore, they are less sensitive to the innovation in aggregate volatility and its adverse effects on product demand.

In this paper I argue that the value of the growth options goes down when aggregate volatility goes up. This notion might seem counterintuitive at first; moreover, it is in conflict with some prior studies on real options, e.g., Eisdorfer (2008), Carlson, Fisher and Giammarino (2004, 2006) and Pindyck (1990). These latter studies assume that as product markets become volatile, aggregate stock prices become volatile as well. Since the value of a growth option is increasing in the volatility of the aggregate product demand - just as the value of a call option is increasing in the volatility of its underlying asset - one would expect a positive relation between the value of the growth option and stock market volatility (and thereby AVS).

However, the assumption that the changes in demand state variable and the returns on the stock market are perfectly correlated is questionable. In fact, Lustig and Van Nieuwerburgh (2008) find that consumption shocks and stock market return innovations are only weakly correlated: The correlation is 0.23 . Moreover, they indicate that (pg. 2110) "based on bootstrapped standard errors, the null hypothesis that this correlation is zero cannot be rejected at the $1 \%$ level." Finally, Carlson et al. (2006) also admit that the risky asset which captures the priced risk in the demand state variable, namely the asset whose returns are perfectly correlated with the changes in the aggregate demand, need not be "the market" (the emphasis is due to the authors).

I argue that the value of the growth options goes down when aggregate volatility goes up by using a direct channel. ICAPM is a useful model which helps us to 
decompose the consumption innovation into its various components. Aggregate volatility shock is a negative consumption innovation which increases the precautionary savings and decreases the aggregate demand. As product demand falls, the growth options become out of the money, and we see a decline in their market value.

After I highlight the importance of aggregate volatility shock as a plausible and statistically significant risk factor for momentum portfolios, it is desirable to test its pricing performance in the presence of other factors. Two such factors are SMB and HML, which, along with the excess market return (Rm-Rf), form the most successful multifactor model in empirical asset pricing. Petkova (2006) shows that they behave like mimicking portfolios for innovations in state variables that describe future investment opportunities. Accordingly, I specify a four-factor model that augments the three factors of Fama-French (1996) with AVS and test the validity of the following unconditional model:

$$
\begin{aligned}
E\left(r_{i t}-r_{f t}\right)=\left(\gamma_{R m-R f}\right)\left(\beta_{i, R m-R f}\right) & +\left(\gamma_{S M B}\right)\left(\beta_{i, S M B}\right)+\left(\gamma_{H M L}\right)\left(\beta_{i, H M L}\right) \\
& +\left(\gamma_{A V S}\right)\left(\beta_{i, A V S}\right)
\end{aligned}
$$

where $\gamma_{R m-R f}, \gamma_{S M B}, \gamma_{H M L}$ and $\gamma_{A V S}$ are the prices of risk for the market excess return $(R m-R f)$, size factor $(S M B)$, book-to-market factor $(H M L)$ and the aggregate volatility shock $(A V S)$, respectively. I test this unconditional model via the Fama-MacBeth (1973) method over the full sample 1941-2009 and over three subsamples. AVS comes from an EGARCH model that has only a constant term in the mean equation.

In this alternative empirical application the sample period starts in 1941 because Jegadeesh and Titman (1993) find that the returns on their relative strength 
strategy over the period 1927-1940 are significantly lower than the returns over their main testing period 1965-1989. They give two reasons to explain this evidence. First, losers had higher bankruptcy risk in the former volatile period. Second, the relative strength strategy performed poorly during the market reversals of the early time period. On the other hand, Jegadeesh and Titman document that the returns over the 1941-1964 time period are similar to the returns over 1965-1989 period. Therefore, it is worth exploring the performance of this alternative multifactor model over the two subperiods analyzed by Jegadeesh and Titman as well as over the subperiod that occurred since their paper was published.

The test assets are 10 equal-weighted momentum portfolios, 12 equal-weighted industry portfolios and 3 factors of Fama and French $(1993,1996)$. These factors are traded portfolios and I include them among my test assets in order to impose the restriction that the cross-sectional price of risk for these factor portfolios should equal to their expected returns in GLS regressions. I have to discard government securities because the sample period starts in 1941, but the data on government bonds are only available since 1952. Table 4 shows the risk premium estimates for the four factor model from equation (4). Cross-sectional regressions reveal that both SMB and HML have insignificant prices of risk, possibly due to the choice of test assets in this study. Fama and French show that their three factor model does not explain the momentum cross-section because losers have higher loadings on SMB and HML than do winners. Moreover, Lewellen et al. (2010) show that adding industry portfolios to the list of test assets reduces the significance level of SMB and HML. On the other hand, the market risk premium of $0.56 \%$ is significant and close to its historical average. Finally, the intercept term, $\gamma_{0}$, is also significant and I reject the unconditional model of expected returns in equation (4). 
Nevertheless, AVS reappears as the main determinant of expected returns on momentum portfolios. The successes of AVS in the previous ICAPM specification continue with this alternative empirical model. For example, the risk premium for AVS is significant in cross-sectional regressions. Winners have lower sensitivity to innovation in aggregate volatility than do losers, and AVS loadings increase monotonically as I move from the winner portfolio to the loser portfolio. Wald tests imply that the loadings of 10 momentum portfolios are jointly significant. Furthermore, I can reject the null hypothesis that loser portfolio and the winner portfolio have equal exposure to aggregate volatility risk. More important, all these results hold over the entire sample period 1941-2009 and over three subperiods. Finally, in unreported regressions with alternative momentum $(\mathrm{J} / 1 / \mathrm{K})$ strategies, I obtain similar results. Therefore, I argue that differences in exposure to aggregate volatility risk across momentum portfolios can account for their return differences.

Recently, Ang, Hodrick, Xing and Zhang (2006) introduce the change in the level of VIX as a proxy for innovation in aggregate volatility. They create a mimicking portfolio for this proxy (FVIX) and test the unconditional model (4) with an alternative group of test assets. As a robustness check, I pick monthly change in VIX as an alternative measure for AVS and test the unconditional models (1) and (4) with my test assets. In unreported regressions I find that the multifactor models that adopt this alternative measure do not price the momentum crosssection. This evidence might seem odd at first glance, but I suggest a possible explanation.

In this paper I argue that momentum profits arise from the negative covariance between winner returns and AVS. Winners hold valuable growth options, but their values decline as AVS hits the economy and decreases the likelihood of 
their exercise. The decline in investment due to a rise in demand uncertainty is an important prediction of real option models and many empirical studies study the relation between real investment and uncertainty. For example, Leahy and Whited (1996) propose a forward looking measure of uncertainty that they derive from the variance of stock returns and document a negative relation between investment and their uncertainty measure. They also evaluate alternative uncertainty measures and they advocate for the use of GARCH type measures if the empiricist has long time series of data. However, they oppose the use of measures that are derived from option prices because the time to maturity of option contracts do not match with the horizon of real investment projects.

Ang et al. (2006) use the change in VIX as their proxy for innovation in aggregate volatility, but this measure is subject to the critique that Leahy and Whited (1996) raise. Whaley (2000) points out that VIX has a thirty calendar day horizon; on the other hand, Chen, Novy-Marx and Zhang (2011) qualitatively show that winners have higher investment-to-assets than losers over the five year holding period (the difference in investment intensity is noticeable during the first two years of the holding period). Moreover, an earlier version of the latter paper shows that winners have higher ROA than losers over the same period. Later in this paper I argue that the investment intensity and the cash flow dynamics of momentum firms determine their payoffs. As a result, the change in VIX is vulnerable to the horizon conflict, whereas AVS from the EGARCH model is not.

Two other papers study aggregate volatility risk in cross-sectional asset pricing. First, Adrian and Rosenberg (2008) study an EGARCH model for market volatility and decompose it into short- and long-run components. They relate the short-run component to market skewness risk and to the tightness of financial constraints; in addition, they argue that the long-run component captures 
the business cycle risk. In cross-sectional regressions, they find negative prices of risk for both components. They use 25 size/book-to-market portfolios as their main test assets, but they show that their results are robust to alternative set portfolios, e.g., a group of 36 test assets that include 10 earnings/price portfolios, 10 cash-flow/price portfolios, 10 dividend yield portfolios and 6 size-momentum portfolios.

Second, Sohn (2010) extends Campbell's (1993) framework by allowing heteroskedastic asset returns and studies the empirical performance of a multifactor model that includes long-run and short-run volatility components that are estimated by means of a GARCH-MIDAS model. In particular, he shows that the long-run volatility component captures the pricing information of SMB, WML and LIQ factor portfolios. He uses 40 test assets: 10 size, 10 book-to-market, 10 momentum $(6 / 1 / 6)$, and 10 liquidity sorted portfolios over the sample period July 1966-December 1999.

My study differs from these two papers in that I explain why aggregate volatility risk matters for momentum portfolios. In this regard, I perform an event time analysis in the manner of Ball and Kothari (1989) in order to explain the short life of momentum profits during the year after portfolio formation. Moreover, I analyze how AVS loadings change after up- and down-market states. I also propose a real option argument and give an economic meaning to AVS loadings. Finally, I show that the reversal of winner returns after the first year of portfolio formation is partly explained by the negative relation between the corporate investment and subsequent returns. In the remainder of this paper, I clarify these arguments in greater detail. 


\section{Event Time Analysis}

An important feature of the momentum puzzle is that the winner-minus-loser profits are short-lived. Jegadeesh and Titman (1993) show that winners have higher average returns than losers during the first year after portfolio formation. Therefore, any risk-based explanation should explain the short life of profits. In order to address this problem, I follow Liu and Zhang (2008) and perform event time factor regressions in the manner of Ball and Kothari (1989).

\subsection{Research Design}

At the end of each portfolio formation month t, I compute the buy-and-hold monthly excess return of momentum portfolios in month $(\mathrm{t}+\mathrm{m})$, where $\mathrm{m}$ ranges from -23 to 24 . The portfolios are reconstructed monthly from December 1942 to December 2007 to represent deciles of past six month return performance. I also skip one month between the end of the ranking period and the start of the holding period. Each decile portfolio has (a) a time series of 633 (t-23) returns covering May 1953-January 2006 period, (b) a time series of 633 ( t) returns covering April 1955-December 2007 period, (c) a time series of $633(\mathrm{t}+24)$ returns covering April 1957-December 2009 period, (d) and a total of 48 such time series, one for every preranking or postranking month $\mathrm{m}$ in event time expressed in relation to the portfolio formation month $\mathrm{t}$. Then, for each of the 48 months, I estimate a system GMM to compute the sensitivities of momentum portfolios to ICAPM factors using 633 months of return data, test the joint significance of these loadings and evaluate the null hypothesis that the winner portfolio and the loser portfolio have equal exposure to aggregate volatility risk. 
The following time series regression defines the loadings of the risk factors for each event-time month $m=-23,-22, \ldots, 0,1, \ldots, 24$ and momentum portfolio $i=$ Loser , 2, ..., 9 , Winner:

$$
\begin{aligned}
R_{i}(m)-R_{f}=\beta_{0}^{i}(m)+ & \beta_{M}^{i}(m) \cdot\left[R_{M}-R_{f}\right]+\beta_{u^{D I V}}^{i}(m) \cdot u^{D I V} \\
& +\beta_{u^{D E F}}^{i}(m) \cdot u^{D E F}+\beta_{u^{T E R M}}^{i}(m) \cdot u^{T E R M} \\
& +\beta_{u^{R F}}^{i}(m) \cdot u^{R F}+\beta_{A V S}^{i}(m) \cdot A V S+\varepsilon_{i}
\end{aligned}
$$

where $\beta_{K}^{i}(m)$ is the loading of the $i$ 'th momentum portfolio on the risk factor $K$ in event month $m$.

\subsection{Results and Discussion}

Table 5 presents the time series evolution of AVS loadings and average WML returns during the preranking and postranking months. The WML portfolio earns significantly positive average returns in each of the 8 months of the postranking period. Interestingly, during this holding period winners have lower AVS loadings than do losers, and there is an almost monotonic increase in AVS loadings as I move from the winner portfolio to the loser portfolio. Moreover, in most event months that follow month 6 of the holding period, losers and winners do not differ in their sensitivity to volatility news. On the other hand, AVS does not explain the reversal of momentum returns beyond the second year of the holding period. For example, in event month 13 the zero cost WML portfolio has an average return of $-0.64 \%$, but I cannot reject the null hypothesis that winners and losers have equal AVS loadings (the p-value for this test is 0.31).

Figure 2 displays the same results by plotting the AVS loadings of winner and loser deciles in event months -23 through +24 . The big difference in AVS 
loadings during the first 6 months of the holding period is striking. It suggests that momentum profits can be driven by the exposure of winner firms to aggregate volatility risk, and that the dispersion in risk across the momentum cross-section is consistent with the dispersion in average returns.

In a similar event time analysis, Jegadeesh and Titman (1993) choose CAPM as their empirical model and estimate equation (5) using only the market portfolio as their risk factor in event months that follow portfolio formation. They find that the market beta of the zero-cost WML portfolio is initially negative and then it steadily increases. They interpret this result as evidence for time-varying risk, but they also reveal the fact that the portfolio's initial risk and the change in risk in later months go in the opposite direction as does the profitability of their momentum strategy.

Moreover, in their 2001 paper, Jegadeesh and Titman advocate for Daniel et al.'s (1998) delayed overreaction model as the main driver of short-term return continuation. According to this behavioral model, investors receive positive signals about some stocks that perform well after the signal arrives. The informed traders attribute the good performance of recent winners to their stock selection ability and the poor performance of recent losers to bad luck. Therefore, these investors feel overconfident about their competence to select winners and about the signals they receive. This overconfidence causes an increase in the prices of winner stocks above their fundamental values. Hence, delayed overreaction generates momentum profits which is ultimately corrected as prices go back to their fundamental values.

I argue, however, that time-varying risk can still be the source of momentum profits. The traditional CAPM that Jegadeesh and Titman (1993) pick for their event time regressions is the cornerstone of all equilibrium finance models; however, it is built on the assumption that the investors are myopic and do not have 
intertemporal hedging concerns. Current studies on macroeconomics and asset pricing, on the other hand, emphasize the importance of consumption smoothing, which creates hedging demand for securities that pay off in low consumption states. Therefore, I argue that an intertemporal CAPM that includes exogenous consumption shocks and represents the hedging concerns of investors can be an alternative benchmark to the traditional CAPM to evaluate the performance of risk-based explanations for the profitability of momentum strategies. In particular, I find that winners have higher expected returns because they are subject to consumption risk as investors increase their precautionary savings in the event of higher market uncertainty.

My study is not the first risk-based story for the temporary nature of momentum profits. In a recent article, Liu and Zhang (2008) accomplish this task by running Ball and Kothari (1989) style event time regressions using MP, the one month ahead industrial production growth rate, as their risk factor. Specifically, they find that winners load more heavily on MP during the first 6 months of the holding period, thereby earning higher average returns than do losers. MP is a business cycle factor and positively related to the aggregate consumption. Therefore, I repeat my event time regressions by adding MP to equation (5) to check whether MP contains the information in AVS. In untabulated regressions I find that the exposure to AVS continues to be an important driver of momentum profits. Winners have negative and significant AVS loadings; in addition, the loadings increase monotonically from winners to losers. On the other hand, winners and losers become equally sensitive to MP in the presence of ICAPM factors.

Table 5 displays other important facts about momentum strategies. First, there is a reversal in loadings during the evaluation period (months -5 through 1). Now losers have negative loadings on AVS, and winners have positive loadings; 
in addition, AVS loadings increase monotonically as I go from the loser portfolio to the winner portfolio. This result is mechanical and arises from the statistical properties of the data. I discuss this problem in greater detail below and provide relevant evidence. Second, during the preevaluation period $(\mathrm{t}-12)$ to $(\mathrm{t}-6)$, the AVS loadings resemble those in the postranking period, e.g. winners load negatively on innovation in aggregate volatility. On the other hand, losers and winners do not differ in their sensitivity to volatility news in preevaluation months $(\mathrm{t}-23)$ through $(\mathrm{t}-13)$. Third, during the preevaluation period $(\mathrm{t}-23)$ to $(\mathrm{t}$ - 15) losers have higher average returns than do winners. This evidence, first documented by Liu, Warner and Zhang (2004) in their Figure 2, adds a new dimension to the momentum puzzle. Apparently, the dispersion of AVS loadings among momentum portfolios is not associated with this return difference.

The main takeaway from Table 5 and Figure 2 is that winners have lower exposure to AVS during the first 6 months of the holding period and this difference in volatility risk coincides with the short life of momentum payoffs. This result also holds in subsamples. To show relevant evidence, I divide the sample of portfolio formation months into two subperiods and repeat the event time regressions for both periods.

In the first subperiod I construct momentum portfolios monthly from April 1955 to December 1981. Figure 3a plots event time AVS loadings of losers and winners in this subperiod. As in Figure 2, winners have lower AVS loadings than losers during the first 6 months of the holding period. In untabulated Wald tests, I can reject the null $H_{0}: \beta_{A V S}^{L}=\beta_{A V S}^{W}$ at the $1 \%$ level for event months $\mathrm{m}=1$, ... , 6. The second subperiod includes portfolio formation months January 1982 through December 2007. Figure 3b tells the same story, and untabulated Wald tests help me reject the null $H_{0}: \beta_{A V S}^{L}=\beta_{A V S}^{W}$ at statistical levels from $2 \%$ to $8 \%$ 
in event months $\mathrm{m}=1, \ldots, 6$. In short, event time analysis results are robust across subsamples.

\subsection{Reversal of AVS loadings over the evaluation period}

As shown in table 5, the WML portfolio has negative AVS loadings both in the preranking period (event months -23 through -6) and in the postranking period (event months 0 through 24), but it has positive AVS loadings in the ranking period (event months -5 through -1 ). This reversal in AVS loadings is a mechanical result produced by three statistical features of the data. First, when I run a simple regression of momentum returns on AVS, I find that winners and losers have equal AVS loadings in almost all of the event months. Second, there is a significant negative correlation between AVS and market excess return (RmRf). I also document this relation in Table 1. Third, market betas of extreme momentum portfolios also reverse over the evaluation period. Liu, Warner and Zhang (2004) run CAPM regressions in event time and find this interesting result. A simple econometric argument that combines these three properties explains why AVS loadings turn in opposite directions.

First, suppose that I regress portfolio returns on a constant and AVS for each month $\mathrm{m}=-23, \ldots, 24$ in event time. This simple regression will give me the AVS

coefficient $b_{i, A V S}(m)=\frac{\operatorname{Cov}\left[R_{i}(m)-R_{f}, A V S\right]}{\operatorname{Var}[A V S]}$ of momentum portfolio $i$ in event month $m$. Figure 4 Panel A reports $b_{i, A V S}(m)$ for the loser portfolio (blue dashed line) and the winner portfolio (red solid line) over event months. Over the evaluation period, both winners and losers covary negatively with AVS. If AVS is positive, the market portfolio has a negative return. In this down market state, losers make big losses. Similarly, if AVS is negative, the market portfolio has a positive 
return. In this up market state, winners make big gains. Interestingly, the simple regression loadings remain stable for both portfolios outside of the evaluation period as well. Moreover, in untabulated Wald tests I cannot reject the null $H_{0}$ : $b_{A V S}^{L}(m)=b_{A V S}^{W}(m)$ for most of the event months. Hence, from now on I assume that $b_{A V S}^{L}=b_{A V S}^{W}$ is valid.

Next, suppose that the ICAPM whose factors are market excess return and AVS is the correct equilibrium model and I run the following time series regression to estimate the factor loadings.

$$
R_{i}(m)-R_{f}=\beta_{i, 0}+\beta_{i, M}(m) \cdot\left[R_{M}-R_{f}\right]+\beta_{A V S}^{i}(m) \cdot A V S+\varepsilon
$$

where $\beta_{i, K}(m)$ is the loading on factor $K$ in event month $m$. Let $X=[1, R m-$ $R f, A V S]$ be the matrix that contains the independent variables of this regression as its column vectors. Then in each event month $m$ the omitted variable formula for least squares regression will give me the following equalities:

$$
\begin{gathered}
E\left[b_{A V S}^{L}(m) \mid X\right]=E\left[b_{A V S}^{W}(m) \mid X\right] \\
\Rightarrow \beta_{A V S}^{L}(m)+\beta_{M}^{L}(m) \cdot \delta=\beta_{A V S}^{W}(m)+\beta_{M}^{W}(m) \cdot \delta \\
\Rightarrow \beta_{A V S}^{W}(m)-\beta_{A V S}^{L}(m)=-\delta \cdot\left[\beta_{M}^{W}(m)-\beta_{M}^{L}(m)\right]
\end{gathered}
$$

where $\delta=\frac{\operatorname{Cov}\left[R_{M}-R_{f}, A V S\right]}{\operatorname{Var}[A V S]}<0$. Equation (6c) shows the relation between the market loading and the AVS loading of the zero cost WML portfolio. I also plot these event-time loadings in panels $\mathrm{B}$ and $\mathrm{C}$ of figure 4 for the loser portfolio (blue dashed line) and the winner portfolio (red solid line). Now the reversal of AVS loadings becomes evident. For example, over the evaluation period (months 
-5 through -1$)$ winners have higher market betas than losers. Then according to equation (6c) winners also have higher AVS loadings than losers over this period. Outside of the evaluation period losers have higher market betas than winners and AVS loadings follow the same pattern.

Hence, the reversal of AVS loadings is an outcome of the reversal of market betas, and the reader might want to know whether there is any rational explanation for the latter problem. Grundy and Martin (2001) provide an explanation. They note that if the market portfolio outperforms Treasury bills, winners will tend to be high beta stocks. Conversely, following down markets, the loser portfolio will contain high beta securities. When I run event time regressions by conditioning on the states of the market over the evaluation period, I can confirm Grundy and Martin's explanation. In addition, the reader can ask whether AVS loadings can be saved and whether winners can have negative AVS loadings over the evaluation period just as they do outside of this period. I provide an answer to this question in Appendix A.

\subsection{Further Evidence on Market States and Momentum}

In a recent study, Cooper, Gutierrez and Hameed (2004) uncover an important fact about momentum payoffs: They depend on the performance of the market portfolio over the past 1 to 3 years. For example, there are positive momentum profits when lagged two year market excess return is nonnegative. Panel A of Table 6 documents this fact in my sample period. The average return on the WML portfolio after a two-year up-market is positive during the first nine months of the holding period. Cooper et al. explain this result with overreaction theory. They argue that investor overconfidence is greater after market gains. The increase 
in overconfidence furthers investor overreaction and leads to higher momentum payoffs.

Alternatively, I argue that the profitability of this conditional momentum strategy can be explained by its exposure to AVS. To test the validity of this argument, I interact AVS with two dummy variables, which represent up and down market states, and run the following event time regression:

$$
\begin{gathered}
R_{i}(m)-R_{f}=\beta_{0}^{i}(m)+\beta_{M}^{i}(m)\left[R_{M}-R_{f}\right]+\sum_{K} \beta_{u^{K}}^{i}(m) \cdot u^{K}+\beta_{A V S}^{i, u p}(m) D^{u p} \cdot A V S \\
+\beta_{A V S}^{i, d o w n}(m)\left(1-D^{u p}\right) A V S+\epsilon
\end{gathered}
$$

where $D^{u p}$ is a dummy variable that equals to 1 if the lagged two-year market performance before the portfolio formation month is nonnegative.

Table 6 displays the outcome of this event time analysis. Panel A shows that losers have higher AVS loadings than winners after an up-market state. For event months $\mathrm{m}=1, \ldots, 6$, the difference in AVS loadings of extreme performing portfolios are significant at the $1 \%$ level. Similar to Cooper et al., I also find that short-run momentum payoffs exclusively follow up-market states. As shown in Panel B of Table 6, the mean return on a zero-cost momentum strategy is insignificant after a two-year down-market; moreover, losers and winners have equal exposure to AVS when such a state occurs.

Economists pay attention to market movements because they contain information about future real activity. Fama (1990) provides evidence for this argument by showing that increases in lagged 1-2 year real market returns forecast positive industrial production growth. Hence the up-market state defined by Cooper et al. (2004) can imply that investors revise upward their expectations about future cash flows and anticipate an economic expansion. Company executives of 
the winner firms also watch the news that the stock market conveys; hence, they are more likely to execute their irreversible investment plans in an up-market state than they are in a down market state. A positive AVS would cause the cancellation of these investment plans and downward revisions in winners' future earnings prospects. Therefore, it is not surprising that winners have negative AVS loadings after an up-market state. In a down-market state, winners hesitate to develop growth options; therefore, their exposure to aggregate volatility risk is not different from losers' exposure.

\section{Evidence on Corporate Investment and Momen- tum Returns}

Besides having different average returns in event time, momentum firms also differ in their real investment activity. For example, Liu and Zhang (2008) and Chen et al. (2011) uncover that winners undertake higher capital spending than losers for a period of two years that starts at the beginning of the evaluation period. In this section, I contribute to this evidence in two important ways. First, I perform an event study to show how aggregate volatility shock affects the investment activity of momentum firms after portfolio formation. I find that AVS predicts negative investment growth for all momentum firms, but that it affects winners more severely. Second, I conduct another event time analysis to study the relation between investment and reversal of momentum returns after the first year of portfolio formation. I find that annual capital spending initiated by winner firms in the middle of the evaluation period is associated with lower subsequent returns. 


\subsection{Data}

I use two types of data in this section. Stock prices and returns come from the monthly CRSP database and accounting data such as capital expenditure, total assets, book equity and earnings come from the CCM (CRSP-Compustat-Merged) quarterly database. Since the accounting data are only available at a quarterly frequency, I follow Sagi and Seasholes (2007) and form my momentum portfolios quarterly. The sample covers the period 1984Q1-2009Q4 because the series for capital expenditure starts in 1984Q1. As in Kothari, Lewellen and Warner (2006), the sample includes only the firms that have March, June, September or December fiscal year ends. This filter enables me to ensure the alignment of fiscal quarters. In addition, at the end of each portfolio formation quarter I apply a $\$ 5$ minimum price filter and drop the stocks that are affected by microstructure problems. Finally, I exclude financial firms from my sample.

\subsection{The Impact of AVS on Corporate Investment}

Mechanically, the market-to-book ratios of winners increase during the evaluation period, so I assume that winners develop growth options and their market values become more sensitive to aggregate demand conditions that affect these options. In the real option model of Carlson, Fisher and Giammarino (2004, 2006) firms hold expansion options, and the optimal investment is characterized by the demand level at which expansion takes place. When product demand falls, firms move away from their optimal investment threshold, so they cannot exercise their growth options. As firms forgo their profit opportunities, investors adjust their earnings forecasts; hence the market values of such firms drop. In this paper, I argue that aggregate volatility shock is the negative demand shock that lowers 
the value of the growth options that winners develop.

Specifically, suppose that the market observes a positive volatility shock and investors increase their precautionary savings. Winner firms respond to this news by cancelling their valuable investment projects. However, this move would induce investors to revise downward their expectations about winners' future cash flows. As a result, an increase in AVS is associated with negative investment growth and thereby negative returns on winners. In section 3 I show that the excess return on the winner portfolio covaries negatively with AVS. In this section I provide evidence for the negative impact of AVS on winners' capital expenditure growth.

At the end of each quarter $t$ stocks with nonmissing accounting and stock return data are allocated into three momentum portfolios. Losers are the $30 \%$ of stocks that have the lowest prior returns. Winners include the top $30 \%$ of performers, and the remaining stocks belong to the middle portfolio. As in previous sections, I compute past returns over a 5 month evaluation period and skip one month to avoid microstructure concerns.

I use a quarterly proxy for AVS, i.e., $A V S=g\left(\frac{\varepsilon_{n}}{\sigma_{n}}\right)+\triangle \cdot g\left(\frac{\varepsilon_{n-1}}{\sigma_{n-1}}\right)+\triangle^{2} \cdot g\left(\frac{\varepsilon_{n-2}}{\sigma_{n-2}}\right)$ for a quarter starting at the beginning of month n-2 and ending at the end of month $\mathrm{n}$. $\triangle$ is the $\operatorname{AR}(1)$ coefficient in the variance equation of an $\operatorname{EGARCH}(1,1)$ model of monthly market excess return. This proxy reflects quarterly revisions in expectations about future market volatility. I assume that AVS hits the market in quarter $t+1$. To estimate its impact on the capital spending of a momentum firm, I create an abnormal investment growth (AIG) measure.

$$
A I G[t+1, t+5]=\frac{i n v[t+1, t+5]}{(i n v[t-15, t-11]+i n v[t-11, t-7]+i n v[t-7, t-3]) / 3}-1
$$

where $i n v[s, s+4]$ is the annual capital expenditure from the end of quarter 
$\mathrm{s}$ to the end of quarter $\mathrm{s}+4$ divided by total assets as of quarter $\mathrm{s}$. AIG measures the change in annual investment activity after the appearance of AVS relative to the average investment activity before the evaluation period. Liu and Zhang (2008) and Chen et al. (2011) show that momentum firms shift their investment policy at the beginning of the evaluation period. Therefore, I exclude the year that precedes quarter $\mathrm{t}+1$ (the time interval from the end of quarter $\mathrm{t}-3$ to the end of quarter $\mathrm{t}+1$ ) in order to obtain a cleaner measure of abnormal investment. Except for the latter adjustment, the measure that I propose is very similar to ones used by Titman et al. (2004) and Anderson and Garcia-Feijoo (2006).

Table 7 reports average AIG at the portfolio level. Winners' investment-toasset ratios increase by $13 \%$ and losers' investment-to-asset ratios decrease by 5\%. Hence, I am able to reproduce Liu and Zhang's (2008) result that winners invest more than losers after portfolio formation. Next, I extend this result in an important direction by investigating how investment changes across momentum stocks when economic agents observe an unexpected increase in market volatility.

I follow Eisdorfer (2008) and estimate the impact of market volatility on firmlevel investment by running a pooled OLS. The dependent variable is AIG from (8) and the independent variables are the quarterly proxy for AVS, the market-tobook ratio, and past annual earnings (ROA). I calculate the values of independent variables at the end of quarter $\mathrm{t}+1$ and interact them with momentum portfolio dummies. This procedure will let me see how the sensitivity of AIG to each regressor differs across momentum portfolios. ${ }^{4}$ In short, I run the following regression:

\footnotetext{
${ }^{4}$ There are some differences between this study and Eisdorfer's study. First, I use a quarterly proxy for AVS (quarterly revision in expectations about future market volatility) in my regressions instead of expected market volatility. Second, I look at the effect of volatility on corporate investment across alternative momentum portfolios, whereas Eisdorfer concentrates on firms that differ in their level of financial distress. Third, I investigate the impact of market volatility on changes in investment while Eisdorfer looks at the impact on the levels.
} 


$$
\begin{aligned}
A I G_{i, t+5}[t+1, t+5]= & b_{L} \cdot X_{i, t+1} \cdot 1_{L, t}+b_{M} \cdot X_{i, t+1} \cdot 1_{M, t} \\
& +b_{W} \cdot X_{i, t+1} \cdot 1_{W, t}+\varepsilon_{i, t+5}
\end{aligned}
$$

where $1_{i}$ is a dummy variable which equals to 1 if the stock belongs to portfolio $i \in\{$ Loser, Middle, Winner $\}$ as of the portfolio formation quarter $\mathrm{t}$ and $X$ is the matrix whose column vectors are the explanatory variables. ${ }^{5}$ Table 7 presents the output of this regression. A positive volatility shock leads to significant declines in investment growth for all firms, and the decline is more pronounced for winners. The estimated coefficient on AVS is $-15.4 \%$ for losers and $-20.7 \%$ for winners, and the $-5.3 \%$ difference is significant at the $1 \%$ level.

\subsection{The Impact of Corporate Investment on Subsequent Returns}

Why are momentum profits short-lived? I argue that winners' risk diminishes as they transform their risky growth options into safer assets-in-place by undertaking investment. I test this hypothesis with an empirical design based on the Fama-MacBeth (1973) method with quarterly data. I follow the event time framework above and form momentum portfolios at the end of quarter t. Then for each quarter in my sample period, I run the following cross-sectional regression:

$$
\begin{gathered}
\tilde{r}_{i,[t+4 Q, t+5 Q]}=\alpha_{t}+\beta_{t} \cdot i n v_{i,[t-1 Q, t+3 Q]} \cdot 1_{L}+\gamma_{t} \cdot i n v_{i,[t-1 Q, t+3 Q]} \cdot 1_{M} \\
+\delta_{t} \cdot i n v_{i,[t-1 Q, t+3 Q]} \cdot 1_{W}+\varepsilon_{i, t+5 Q}
\end{gathered}
$$

\footnotetext{
${ }^{5}$ The dependent variable in equation (9) uses overlapping capital expenditure data; therefore, I use a Newey-West (1987) procedure, modified for panel data, to compute the t-statistics.
} 
where I regress firm excess returns at the end of quarter $\mathrm{t}+5 \mathrm{Q}\left(\tilde{r}_{i,[t+4 Q, t+5 Q]}\right)$ on variables that are known at the end of quarter $\mathrm{t}+4 \mathrm{Q} .{ }^{6}$ The independent variables in Fama-MacBeth cross-sectional regressions are the investment-asset ratio that I interact with momentum portfolio dummies and the evaluation period return $\left(r_{i,[t-6, t-1]}\right)$. The accounting data will come from Compustat quarterly database.

Table 8 presents the results of this analysis. The first regression shows the well-known reversal phenomenon in asset pricing. Stocks that perform well in the recent past earn lower returns after one year. The second regression reproduces the negative relation between investment and subsequent average returns documented by Fama and French (2006), Cooper, Gulen and Schill (2008), Titman et al. (2004) and Anderson and Garcia-Feijoo (2006). Fama and French measure real investment by asset growth. Cooper et al. (2008) decomposes asset growth into its balance-sheet components and find that the investment-to-asset ratio is a major component determining the negative relation between asset growth and subsequent returns. Titman et al. (2004) create a proxy for abnormal investment by comparing the investment-to-sales ratio to its three year average in previous years. Anderson and Garcia-Feijoo use capital expenditure growth over the past two years as their independent variable. I use investment-to-asset ratio in quarterly Fama-MacBeth (1973) regressions and find a significant negative relation between the capital expenditure of winners and their return reversal after the first year of portfolio formation.

In a recent study, Chen, Novy-Marx and Zhang (2011) uncover that winners

\footnotetext{
${ }^{6}$ Sagi and Seasholes (2007) also use quarterly accounting data in their momentum study and assume one quarter gap between the realization of accounting numbers and their announcement. Grullon, Lyandres and Zhdanov (2010) estimate a similar regression to equation (10) where they explore the cross-sectional relation between firm level volatility and average stock returns for firms that belong to different real option portfolios. They use annual accounting data in their analysis.
} 
have higher investment-to-asset than losers over the period [t-1Q, t+3Q] and I am able to generate similar results in my sample. Average annual investment as a fraction of total assets $\overline{i n v_{[t-1 Q, t+3 Q]}}$ amounts to $9.69 \%$ for winners and $7.85 \%$ for losers and the difference is statistically significant. The high level of investment from quarter $\mathrm{t}-1 \mathrm{Q}$ to quarter $\mathrm{t}+3 \mathrm{Q}$ undertaken by winners means that these firms transform their risky growth options into safer assets-in-place; as a result, investors demand lower risk premia after this transformation. The Regression 4 in Table 8 estimates the coefficients in equation (10) and provides further evidence in favor of this argument. The negative relation between investment and subsequent average returns distinguishes winners from other momentum stocks.

\section{Comparison with Conditional CAPM}

In this section I compute the time varying risk of momentum stocks over the business cycle by estimating a conditional capital asset pricing model in the manner of Petkova and Zhang (2005). I use the dividend yield, default premium, term premium and the risk-free rate as my conditioning variables in order to estimate the market risk premium. Conditional CAPM reveals that losers (winners) are riskier than winners (losers) during trough (peak) times when the expected market premium is high (low).

\subsection{Testing Procedure}

First, I estimate the market risk premium by regressing the realized excess market return on conditioning variables in my information set:

$$
r_{m, t}=\delta_{0}+\delta_{1} \cdot D I V_{t-1}+\delta_{2} \cdot D E F_{t-1}+\delta_{3} \cdot T E R M_{t-1}+\delta_{4} \cdot R F_{t}+\varepsilon_{i, t}
$$


where the fitted component yields the expected market risk premium $\hat{\gamma}_{i, t}=$ $\hat{\delta}_{0}+\hat{\delta}_{1} \cdot D I V_{t-1}+\hat{\delta}_{2} \cdot D E F_{t-1}+\hat{\delta}_{3} \cdot T E R M_{t-1}+\hat{\delta}_{4} \cdot R F_{t}$. The choice of these predictive variables is also consistent with my earlier ICAPM specification.

After I compute the fitted component, I define four states of the economy in the manner of Petkova and Zhang (2005). State "peak" corresponds to the $10 \%$ lowest observations of the market premium; state "expansion" refers to observations below average premium; state "recession" refers to sample periods with above average premium, excluding the $10 \%$ highest observations; and state "trough" corresponds to observations with the highest $10 \%$ expected market risk premium. I use these cyclical indicators to examine how the conditional betas of momentum stocks vary over the business cycle.

Next, I run conditional market regressions to estimate the conditional betas:

$$
\begin{gathered}
r_{i, t}=\alpha_{i}+\left(b_{i 0}+b_{i 1} \cdot D I V_{t-1}+b_{i 2} \cdot D E F_{t-1}+b_{i 3} \cdot T E R M_{t-1}\right. \\
\left.+b_{i 4} \cdot R F_{t}\right) \cdot r_{m, t}+\varepsilon_{i, t}
\end{gathered}
$$

Here the expression $\hat{\beta}_{i, t}=\hat{b}_{i, 0}+\hat{b}_{i, 1} \cdot D I V_{t-1}+\hat{b}_{i, 2} \cdot D E F_{t-1}+\hat{b}_{i, 3} \cdot T E R M_{t-1}+$ $\hat{b}_{i, 4} \cdot R F_{t}$ gives me the conditional beta of the $i^{t h}$ momentum stock where $i \in$ $\{U p$, Down, UMD $\}$. The Up (Down) portfolio is the average of the small winner (loser) portfolio return and large winner (loser) portfolio return. UMD is the Up-Minus-Down portfolio, which is also the momentum factor of Ken French.

Finally, I regress the fitted betas on the economic state indicators and test whether they vary from the peak of the business cycle to its bottom. 


\subsection{Results and Discussion}

Table 9 presents the results. In Panel A, I report the market risk premium and the conditional betas. Winners have higher conditional betas during peak times (when the expected market premium is low) than they do during trough periods. The conditional beta of the Up portfolio is 1.20 in the peak state and 0.93 in the trough state, and the difference is statistically reliable. On the other hand, losers have higher conditional betas during the trough periods (when the expected market premium is high) than they do during peak times. The conditional beta of the Down portfolio is 1.13 in the peak state and 1.36 in the trough state, and the difference is statistically reliable.

Jagannathan and Wang (1996) argue that during bad economic periods when the expected market risk premium is relatively high, more leveraged firms are more likely to encounter financial problems and thus have higher conditional betas. On the other hand, if the uncertainty associated with future growth opportunities is the cause for higher risk, then conditional betas will be relatively low during bad economic periods. Jagannathan and Wang attribute the latter result to the decrease in the uncertainty and the value of future growth opportunities during bad times; moreover, they argue that this effect can even offset the effect of increased leverage.

Winners' risk comes mainly from the growth opportunities that they possess in good times. On the other hand, losers are likely to be financially distressed, and they face high bankruptcy risk in recessionary periods. In this regard, the variation of conditional betas of these extreme momentum portfolios over the business cycle is in line with the above argument. However, Jagannathan and Wang (1996) also show that if the conditional beta of an asset covaries with the 
market risk premium, then this asset should earn high average (unconditional) returns. According to this derivation, losers should earn higher average returns than do winners, but this prediction contradicts with the facts.

Recently, Daniel and Moskowitz (2011) propose a conditional CAPM framework to explain the momentum crashes (negative WML strategy returns) after market declines. Specifically, they define up and down market states in the manner of Cooper et al. (2004): The investors observe an ex-ante bear market when the two year prior market return is negative. Afterwards, Daniel and Moskowitz use the ex ante bear market indicator as their conditioning variable in conditional CAPM. They find that the market beta of the WML portfolio is -1.16 lower in bear market state than its beta in bull market state.

Prior negative market returns signal recessions in which the expected market risk premia are high. In this paper, I use alternative conditioning variables to define the state of the economy, but I find evidence which is similar to the evidence shown in Daniel and Moskowitz (2011). Panel A of Table 9 documents that in trough periods the market beta of the UMD portfolio is 0.5 lower than its beta in peak periods.

Even though conditional CAPM reveals important economic insights about the time varying nature of risk, it does not explain the momentum anomaly. Another example against its validity for the cross-section of momentum stocks comes from alpha estimates in conditional market regression (12). If this asset pricing model explains the momentum premium, the alpha for the UMD portfolio should be zero. On the contrary, as shown in Panel B of Table 12, UMD has an alpha of $0.92 \%$, and it is statistically significant. This pricing error is very high because the average return on the UMD portfolio is $0.76 \%$ over the sample period.

Since conditional CAPM performs poorly in accounting for the momentum 
profits, we need to divert our attention to alternative empirical models. This paper introduces Chen's (2003) ICAPM with aggregate volatility shock as a candidate empirical model.

\section{Further Evidence on Momentum Anomaly}

\subsection{Information Uncertainty or Existence of Growth Op- tions}

In a recent study on momentum puzzle, Zhang (2006) finds that small (young) winners have higher average returns than do large (mature) winners. In his work, size and age proxy for information uncertainty. Zhang uses Daniel et al.'s (1998) argument that return predictability is higher for stocks with greater uncertainty because investors' overconfidence increases when it becomes hard to value firms' businesses.

Real option scholars, on the other hand, argue that firm size and age can proxy for the importance of growth opportunities in determining the firm value. For example, small and young firms have fewer ongoing projects; hence, their values depend on the investment opportunities that they possess. On the other hand, in large, old and more established companies existing assets contribute more to the firm value than do investment opportunities. In my paper I argue that winners develop growth options over the ranking period; hence, they become vulnerable to negative demand shocks, in particular to aggregate volatility shock which makes these options out of the money and causes a decline in their values. Therefore, it 
seems reasonable to argue that small (young) winners would have a more negative AVS loading and thereby higher expected returns than do large (mature) winners. I repeat the Fama-MacBeth (1973) method by substituting 25 size/momentum (age/momentum) for 10 momentum portfolios. Untabulated cross-sectional regressions yield negative risk premium estimates for aggregate volatility shock. In Table 10 Panel A, I report the AVS loadings of size/momentum portfolios, and the p-values from Wald tests. Panel B displays the corresponding statistics for 25 age/momentum stocks. Within each size or age quintile, winners have a more negative sensitivity to market volatility news; therefore, they have higher average returns than do losers. More interestingly, within the winner quintile, AVS loadings decline monotonically from the large (mature) portfolio to the small (young) portfolio. I can also reject the null hypothesis that small (young) winners have the same exposure to AVS as large (mature) winners. Hence, differences in exposure to AVS can be an alternative explanation for the profitability of small (young) winners.

\subsection{ICAPM with VIX Innovations}

A key argument in my paper is that differences in investment activity of momentum firms after portfolio formation affect the cross-sectional dispersion in their average returns. Prior momentum literature documents that during the first year of the holding period winners have higher average returns than do losers; moreover, the former group undertakes a more intensive investment activity than the latter group for about two years. I argue that a positive volatility shock terminates the investment plans of winners; thereby reducing their market value. 
Aggregate volatility news has a long run impact on firm investment policies; therefore, its horizon should match with that of the real projects. Leahy and Whited (1996) advocate using volatility measures derived from time series models, because these measures capture the volatility dynamics at any horizon. On the other hand, they oppose to the use of volatility proxies that are derived from option prices because the time to maturity of option contracts do not match with the horizon of real investment projects.

One common measure of aggregate volatility shock is changes in VIX. Ang et al. (2006) introduce this measure as a plausible risk factor in an ICAPM framework and provide evidence in favor of its usage in asset pricing tests. Therefore, it seems worthwhile to check the robustness of the results to this measure derived from option prices.

The results are not robust. As shown in Panel A of Table 11, the loadings on monthly changes in VIX are not consistent with the dispersion in average returns on momentum stocks. In addition, I cannot the reject the null hypothesis that winners and losers have equal exposure to aggregate volatility news. This result is driven by the characteristics of this specific volatility measure. VIX has a month horizon, and it is vulnerable to the critique of Leahy and Whited (1996). An alternative volatility measure computed from the VIX term structure provides a significant improvement in the alignment of loadings with returns; moreover, it is immune to the critique of Leahy and Whited.

I construct an alternative volatility measure by using VIX measures that have longer time to maturity. These measures come from Travis Johnson's website. ${ }^{7}$ Johnson (2012) calculates the VIX term structure by using the same method as the publicized VIX but with longer times-to-expiration than one month. The

\footnotetext{
${ }^{7}$ http://www.stanford.edu/ travisj/data.html
} 
term structure contains VIX at one-, two-, three-, six-, nine-, and twelve-month horizons, and is calculated daily throughout his sample starting in 1996. Of these VIX measures I pick the monthly observations of $V I X_{12}, V I X_{1}$ and $V I X_{2}$ and run the following regression to compute the news component of long term stock market volatility:

$V I X_{12}=a_{0}+a_{1} \cdot V I X_{1}+a_{2} \cdot V I X_{2}+a_{3} \cdot A R(1)+a_{4} \cdot S A R(12)+\varepsilon_{V I X}^{A V S}$

where the residual term $\left(\varepsilon_{V I X}^{A V S}\right)$ is my AVS measure based on the VIX term structure. It is orthogonal to short term market volatility proxied by $V I X_{1}$ and $V I X_{2}$ - The $\mathrm{AR}(1)$ term accounts for the first order autocorrelation in $V I X_{12}$ and the seasonal autoregressive $\operatorname{SAR}(12)$ term accounts for the 12-month seasonal periodicity. The residual term is white noise. (The p-value of the $\mathrm{Q}(12)$ statistic is 0.339.)

Panel B of Table 11 reports the output of regression (13). When I control for $V I X_{2}$ we obtain a negative coefficient for $V I X_{1}$. Johnson (2012) analyzes the evolution of the VIX term structure and highlights that the term structure slopes downward (upward) when the one month VIX is particularly high (low). He argues that investors assume some mean reversion in market volatility and that the volatility becomes normal over the next year.

Panel $\mathrm{C}$ of Table 11 presents the sensitivities of momentum stocks to the alternative AVS measure computed from the VIX term structure. The loadings are jointly significant, and they decline monotonically from the loser portfolio to the winner portfolio and I can reject the null hypothesis that winners and losers have the same exposure to innovation in aggregate volatility. Hence, the dispersion in aggregate volatility risk aligns with the dispersion in average returns. However, 
one needs to evaluate this result with an important caveat. In untabulated FamaMacBeth (1973) cross-sectional regressions, I find a negative, albeit insignificant, price of risk for this new AVS proxy. The sign of the risk premium is in line with the predictions of ICAPM, but it has low statistical power.

\section{Conclusion}

Momentum profits are generated by winners' exposure to aggregate volatility risk. A proxy for the aggregate volatility shock (AVS), which comes from an EGARCH $(1,1)$ model for monthly market excess returns, is a priced risk factor in FamaMacBeth (1973) regressions and commands a negative risk premium. Winners have negative AVS loadings, thereby earning higher average returns.

The motivation to use AVS as a plausible risk factor comes from consumptionbased asset pricing. An intertemporal CAPM representing the hedging demands of investors helps me find the relevant consumption shock that prices the momentum cross-section. I choose a pricing kernel that includes AVS together with market excess return and innovations in predictive variables as its factors. In this pricing kernel, AVS features as the main risk factor and explains the cross-sectional return variation of momentum portfolios.

The temporary nature of momentum profits is an important dimension of the momentum puzzle and the empirical model of this paper offers important insights into this dimension. Using the event time regression framework of Ball and Kothari (1989) I show that winners have lower AVS loadings than losers over the holding period, and that the difference in loadings becomes mostly insignificant 
after 6 months. Another event time study shows that the profitability of momentum strategies after up-market states can also be attributed to the difference in aggregate volatility risk. Behavioral studies on momentum explain the short-run return continuation with the delayed overreaction theory of Daniel et al. (1998). According to this theory, investors feel overconfident about their ability to select winners and such overconfidence causes an increase in winners' prices. In this paper, I take a different approach and propose time-varying aggregate volatility risk as an alternative to behavioral explanations.

I explain the negative AVS loadings of winners with a real option argument. Over the evaluation period, winner firms develop growth options and their market values become sensitive to aggregate demand conditions. AVS is a negative demand shock and leads to precautionary savings. As AVS signals a decline in product demand, the executives that run winner firms shift their investment policy and do not exercise their growth options. This shift induces stock market participants to downgrade their expectations about future cash flows that winner firms would generate. I find that the deterioration in investment growth after a positive volatility surprise is bigger for winner firms. Lower growth prospects also imply greater loss in market value.

Finally, the reversal of momentum returns one year after portfolio formation is partly explained by the negative cross-sectional relation between real investment and expected returns. Like all firms, the winner firm is a combination of assets in place and growth options, but at the end of the portfolio formation month, growth options increase their share in the valuation equation. As the winner firm invests over the first year of the holding period, risky growth options lose their priority. Hence, the overall risk of the winner firm declines and investors demand lower risk premium. 


\section{References}

[1] Adrian T., Rosenberg J., 2008, Stock Returns and Volatility: Pricing the Short-Run and Long-Run Components of Market Risk, Journal of Finance, 63, 6, 2997-3030.

[2] Anderson, C. W., and L. Garcia-Feijoo, 2006, Empirical Evidence on Capital Investment, Growth Options, and Security Returns, Journal of Finance, 61 (1), 171-194.

[3] Ang A., Hodrick R., Xing Y., Zhang X., 2006. The Cross-Section of Volatility and Expected Returns. Journal of Finance, 61, 1, 259-299.

[4] Ball, R., and S. P. Kothari, 1989, Nonstationary Expected Returns: Implications for Tests of Market Efficiency and Serial Correlation in Returns, Journal of Financial Economics, 25, 51-74.

[5] Campbell, J, 1993. Intertemporal asset pricing without consumption data, American Economic Review 83, 487-512.

[6] Campbell, J, 1996. Understanding risk and return. Journal of Political Economy 104, 298-345.

[7] Cao C.Q. and R.S. Tsay, 1992, Nonlinear Time-Series Analysis of Stock Volatilities, Journal of Applied Econometrics, 7, S165-S185.

[8] Carhart, M., 1997. On Persistence in Mutual Fund Performance. Journal of Finance 52, 57-82. 
[9] Carlson, M., Fisher, A., Giammarino, R., 2004. Corporate investment and asset price dynamics: implications for the cross section of returns. Journal of Finance 59, 2577-2603.

[10] Carlson, M, Fisher A., and R. Giammarino, 2006, Corporate Investment and Asset Price Dynamics: Implications for SEO Event Studies and Long-Run Performance, Journal of Finance, 3, 1009-1034

[11] Chan, Louis K. C., Josef Lakonishok, and Theodore Sougiannis, 2001, The Stock Market Valuation of Research and Development Expenditures, Journal of Finance, 56, pp. 2431-2456.

[12] Chen, J., 2003, Intertemporal, CAPM and the cross-section of stock returns, Working paper, University of Southern California.

[13] Chen, L., Novy-Marx R., and L. Zhang, 2011, An Alternative Three-Factor Model, Working Paper.

[14] Chen, N. F., R. Roll, and S. A. Ross, 1986, Economic Forces and The Stock Market, Journal of Business, 59 (3), 383-403.

[15] Cooper, Michael J., Huseyin Gulen, and Michael J. Schill, 2008, Asset growth and the cross-section of stock returns, Journal of Finance 63, 1609-1652.

[16] Cooper, Michael J., Roberto C. Gutierrez Jr., and Allaudeen Hameed, 2004, Market states and momentum, Journal of Finance 59, 1345-1365.

[17] Daniel, Kent, David Hirshleifer, and Avanidhar Subrahmanyam, 1998, Investor psychology and security market under- and overreactions, Journal of Finance 53, 1839-1886. 
[18] Daniel K., and T. Moskowitz (2011), Momentum Crashes, Columbia University and University of Chicago.

[19] DeBondt W., Thaler R. 1987. Further evidence on investor overreaction and stock market seasonality. Journal of Finance 42, 557-581.

[20] Eisdorfer, A., 2008. Empirical evidence of risk-shifting in financially distressed firms. Journal of Finance 63 (2), 609-637.

[21] Fama, E. F., 1990. Stock returns, expected returns, and real activity. Journal of Finance 45, 1089-1108.

[22] Fama, E. F., and J. D. MacBeth, 1973, Risk return, and equilibrium: Empirical tests, Journal of Political Economy 71, 607-636.

[23] Fama, E. F., and K.R. French, 1988, Dividend Yields and Expected Stock Returns, Journal Financial Economics 22, 3-25.

[24] Fama, E.F., French, K., 1989. Business conditions and expected returns on stocks and bonds. Journal of Financial Economics 25, 23-49.

[25] Fama, E. F., and K. R. French, 1993, Common Risk Factors in the Returns on Stocks and Bonds, Journal of Financial Economics, 33, 3-56.

[26] Fama, E.F., French, K., 1996. Multifactor explanations of asset pricing anomalies. Journal of Finance 51, 55-84.

[27] Fama, E. F., and K. R. French. 2006. Profitability, Investment and Average Returns. Journal of Financial Economics 82: 491-518.

[28] Fama, E.F., Schwert, G.W. 1977, Asset returns and ination. Journal of Financial Economics 5, 115-146 
[29] French, K. R., G. W. Schwert, and R. F. Stambaugh, 1987, Expected stock returns and volatility, Journal of Financial Economics 19, 3-29.

[30] Grullon G., Lyandres E. and A. Zhdanov. 2010. Real Options, Volatility, and Stock Returns, Working Paper.

[31] Grundy, B. D., and J. S. Martin, 2001, Understanding the Nature of the Risks and the Source of the Rewards to Momentum Investing, Review of Financial Studies, 14 (1), 29-78.

[32] Jagannathan, R., Wang Z., 1996. The conditional CAPM and the crosssection of expected returns. Journal of Finance 51, 3-53.

[33] Jegadeesh, N., 1990, Evidence of predictable behavior of security returns, Journal of Finance 45, 881-898.

[34] Jegadeesh, N., and S. Titman, 1993, Returns to Buying Winners and Selling Losers: Implications for Stock Market Efficiency, Journal of Finance, 48, $65-91$.

[35] Jegadeesh, N., and S. Titman, 2001, Profitability of momentum strategies: An evaluation of alternative explanations, Journal of Finance 56, 699-720.

[36] Johnson, T. C., 2002. Rational Momentum Effects. Journal of Finance, 57 (2), 585-608.

[37] Johnson, T. 2012. Equity Risk Premia and the VIX Term Structure, working paper, Stanford University.

[38] Kothari, S.P., J. Lewellen, and J. B. Warner, 2006. Stock returns, aggregate earnings surprises and behavioral finance. Journal of Financial Economics, $79,537-568$. 
[39] Leahy, J. V., and T. M. Whited, 1996, The effect of uncertainty on investment: Some stylized facts, Journal of Money, Credit, and Banking 28, 64-83.

[40] Lewellen, J. Nagel S., Shanken J, 2010. A skeptical appraisal of asset pricing tests. Journal of Financial Economics 96, 175-194.

[41] Lettau, Martin, and Sydney Ludvigson, 2001, Resurrecting the (C)CAPM: A cross-sectional test when risk premia are time-varying, Journal of Political Economy 109, 1238-1287.

[42] Liu, L.X., J. B. Warner and L. Zhang, 2004, Economic Fundamentals, Risk, and Momentum Profits, Working Paper, University of Rochester.

[43] Liu, L.X. and L. Zhang, 2008, Momentum Profits, Factor Pricing and Macroeconomic Risk, Review of Financial Studies, 21(6), 2417-2448.

[44] Liu, L.X. and L. Zhang, 2011, Investment-Based Momentum Profits, Working Paper, Hong Kong University of Science and Technology and Ohio State University.

[45] Ljung G. and Box G. E. P. 1978, On a measure of lack of fit in time series models. Biometrika, 66, 67-72.

[46] Lustig H. and S. Van Nieuwerburgh. 2008, The Returns on Human Capital: Good News on Wall Street is Bad News on Main Street. Review of Financial Studies, 21, 5, 2097-2137.

[47] Merton, R., 1973. An intertemporal capital asset-pricing model. Econometrica $41,867-887$. 
[48] Newey, W.K., West, K.D., 1987. A simple, positive semidefinite, heteroskedasticity and autocorrelation consistent covariance matrix. Econometrica $55,703-708$.

[49] Petkova, R., 2006. Do the Fama-French Factors Proxy for Innovations in Predictive Variables? Journal of Finance 61, 581-612.

[50] Petkova, R., Zhang, L., 2005. Is value riskier than growth? Journal of Financial Economics 78, 187-202.

[51] Titman, S., Wei, K.C.J., Xie, F., 2004. Capital investments and stock returns. Journal of Financial and Quantitative Analysis 39, 677-700.

[52] Sagi, J. S., and M. S. Seasholes, 2007, Firm-specic attributes and the crosssection of momentum, Journal of Financial Economics 84, 389-434.

[53] Shanken, J. A., 1992, On the Estimation of Beta-Pricing Models, Review of Financial Studies, (5) 1, 1-33.

[54] Sohn, B. 2010. Stock Market Volatility and Trading Strategy Based Factors, Working Paper, Georgetown University.

[55] Whaley, R., 2000, The investor fear gauge, Journal of Portfolio Management $26,12-17$.

[56] Zhang, X. Frank, 2006, Information uncertainty and stock returns, Journal of Finance 61, 105-136. 
Table 1: Aggregate Volatility Shock $(A V S)$

This table presents the parameter estimates from the EGARCH $(1,1)$ model for monthly excess market returns and the descriptive statistics of the aggregate volatility shock derived from the EGARCH model. In Panel A, I specify the mean and variance equations of the EGARCH model and report the parameter estimates. The parameter estimates for $\theta$ and $\gamma$ and the standardized residual $\frac{\varepsilon_{t}}{\sigma_{t}}$ series are used the to calculate the aggregate volatility shock (AVS),

$g\left(\frac{\varepsilon_{t}}{\sigma_{t}}\right)=\theta \cdot \frac{\varepsilon_{t}}{\sigma_{t}}+\gamma \cdot\left(\left|\frac{\varepsilon_{t}}{\sigma_{t}}\right|-\sqrt{\frac{2}{\pi}}\right)$. Panel B displays the mean, the standard deviation of AVS, the p-value associated with the Ljung-Box (1978) statistic for 12 lags of autocorrelation function, the correlation coefficient of AVS with excess market return and three alternative measures for innovation in aggregate volatility. The first measure is the unpredicted component of aggregate volatility $\sigma_{m, t}^{2 u}$ computed from the ARIMA model of French, Schwert and Stambaugh (1987). The second measure $\varepsilon_{t}^{2}-\sigma_{t}^{2}$ is the volatility shock associated with the GARCH $(1,1)$ model. The third measure is the change in the monthly level of VIX $\left(\Delta_{m} V I X\right)$ and is only available from January 1986 to December 2009. Panel B also presents the output of the regression of AVS on Carhart's (1997) four factor model. The sample spans the period May 1953-December 2009. 


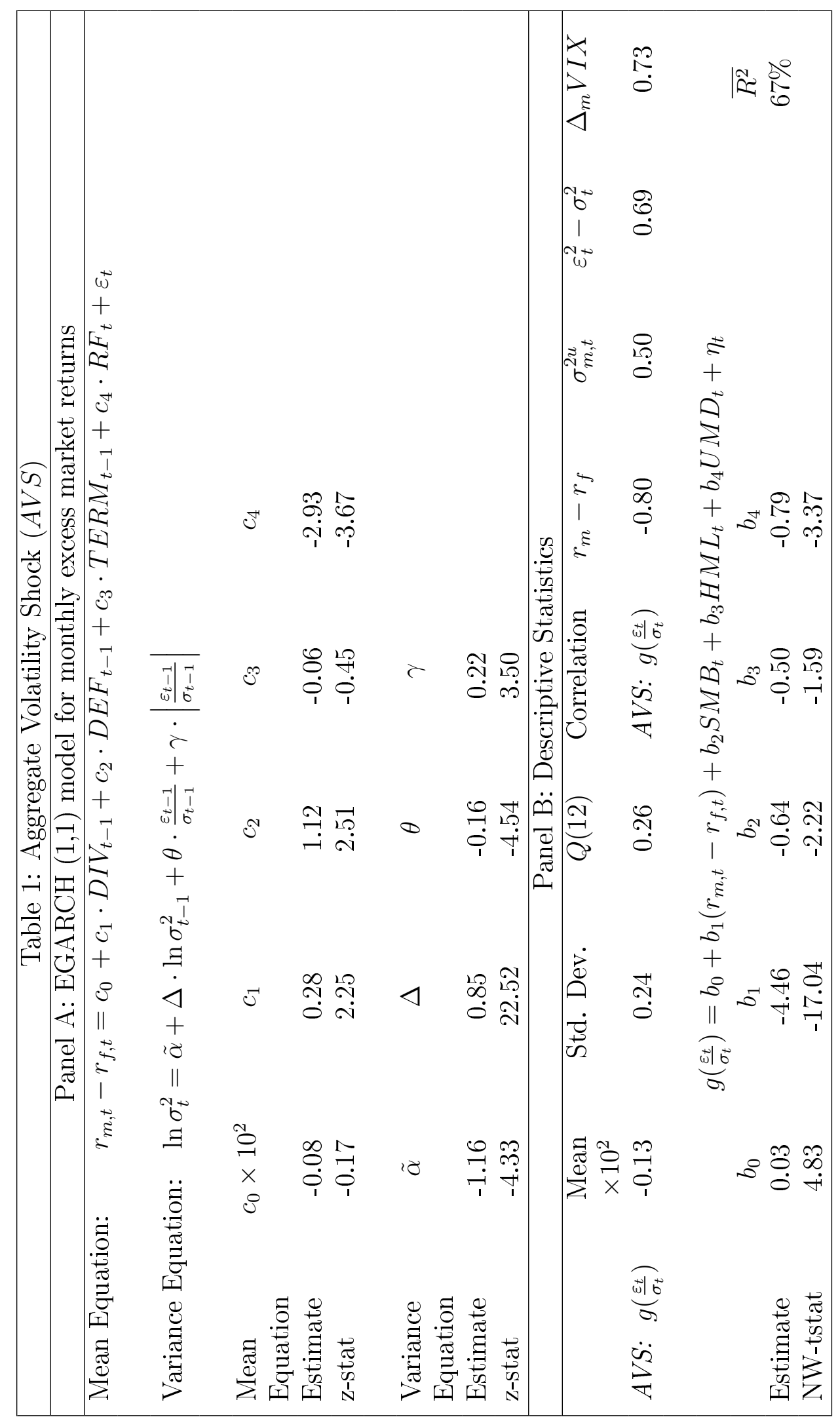




\section{Table 2: Fama-MacBeth (1973) Method: ICAPM with EGARCH $(1,1)$ model}

This table presents the output of Fama-MacBeth (1973) cross-sectional regressions. The multifactor model is an unconditional model that uses excess market return $r_{m}-r_{f}$, innovations in predictive variables and aggregate volatility shock (AVS) as factors. I follow Petkova (2006) and run a first order VAR to generate unorthogonalized innovations in dividend yield, default premium, term premium and riskfree rate. $A V S$ is the weighted innovation of the EGARCH $(1,1)$ model from Table 1 . The test assets are excess returns on 10 equal-weighted momentum $(6 / 1 / 6)$ portfolios, 12 equal-weighted industry portfolios, short term government bond, long term government bond and the market. Panel A displays the results of the Fama-MacBeth method over the full sample period May 1953-December 2009 and the other panels show the subperiod evidence. For each cross-sectional regression, I report the estimates of risk premia $\gamma$ (reported in \% form), Fama-MacBeth (1973) and Shanken (1992) t-statistics, and two goodness of fit measures, namely the OLS $R^{2}$ of Jagannathan and Wang (1996) and the GLS $R^{2}$ suggested by Lewellen, Nagel and Shanken (2010). In addition, each panel displays time-series regression outputs. Specifically, I report AVS loadings, their robust standard errors (both statistics are shown in percentage form) and the p-values from the following Wald tests that are performed after a GMM-HAC system estimation. $H_{0}: \beta_{A V S}^{m o m}=0$ tests the joint significance of $10 \times 1$ vector of loadings of momentum

portfolios. $H_{0}: \beta_{A V S}^{L}=\beta_{A V S}^{W}$ tests the null hypothesis that loser portfolio and winner portfolio have equal loadings on aggregate volatility shock. 


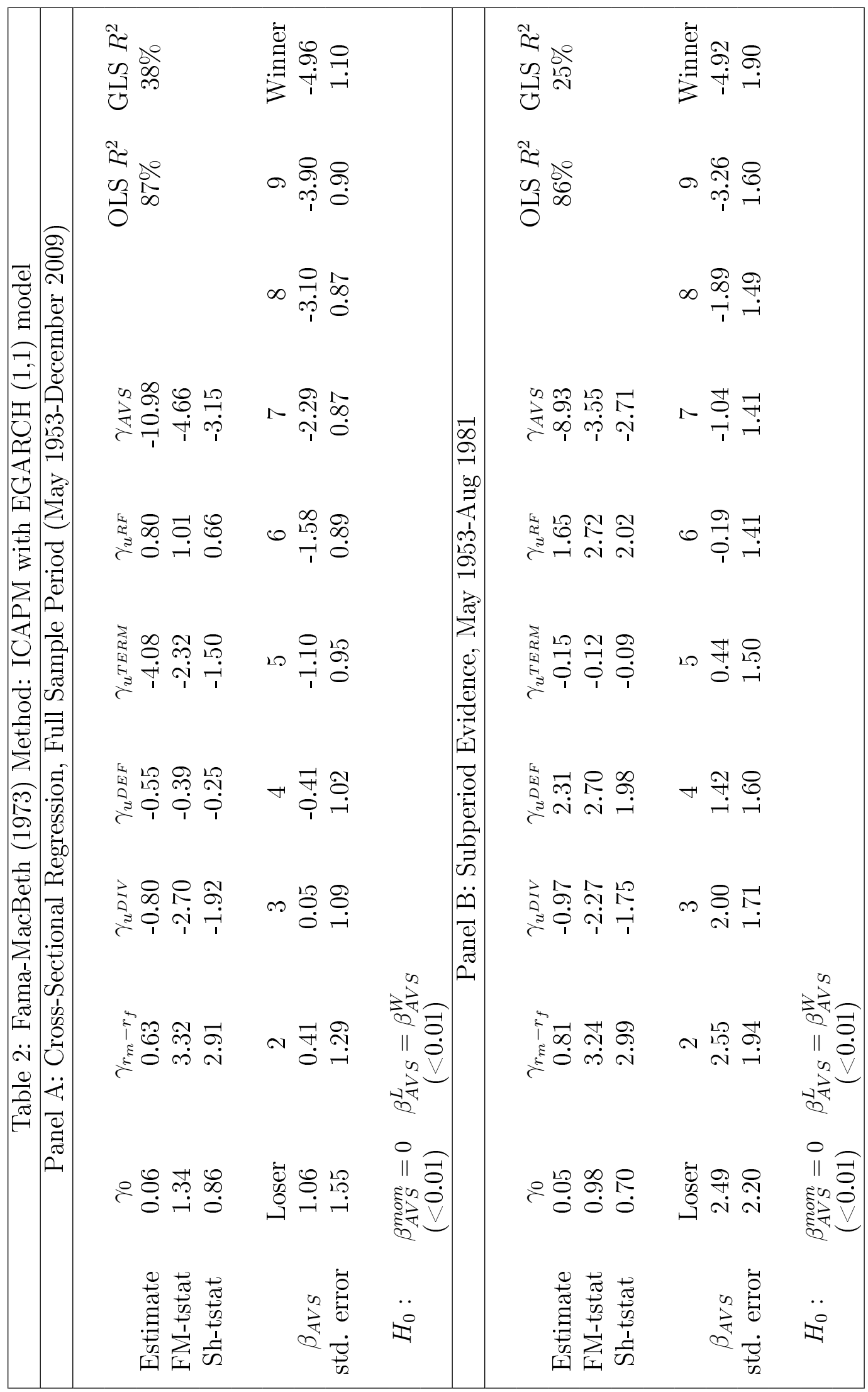









\section{Table 3: Alternative Momentum Strategies}

This table documents the robustness of results to the employment of alternative momentum strategies. The multifactor model is an unconditional model that uses $r_{m}-r_{f}$, innovation in predictive variables and aggregate volatility shock as factors. AVS is estimated from an EGARCH $(1,1)$ model for monthly excess market returns. I form each strategy by changing the evaluation period $J$ and holding period $K$. I also skip one month between the end of the evaluation period and the start of the holding period. The rows display different sorting periods in ascending order from 12 months to 3 months and the columns display different holding periods from 12 months to 1 month. Panel A presents AVS loadings of the winner-minus-loser $(W M L)$ portfolio (reported in percentage form) and the corresponding Newey-West (1987) t-statistics (in parentheses). Panel B presents the estimates of price of risk for $A V S$ (reported in percentage form) and and Shanken (1992) t-statistics (in parentheses). The sample spans the period May 1953-December 2009. 


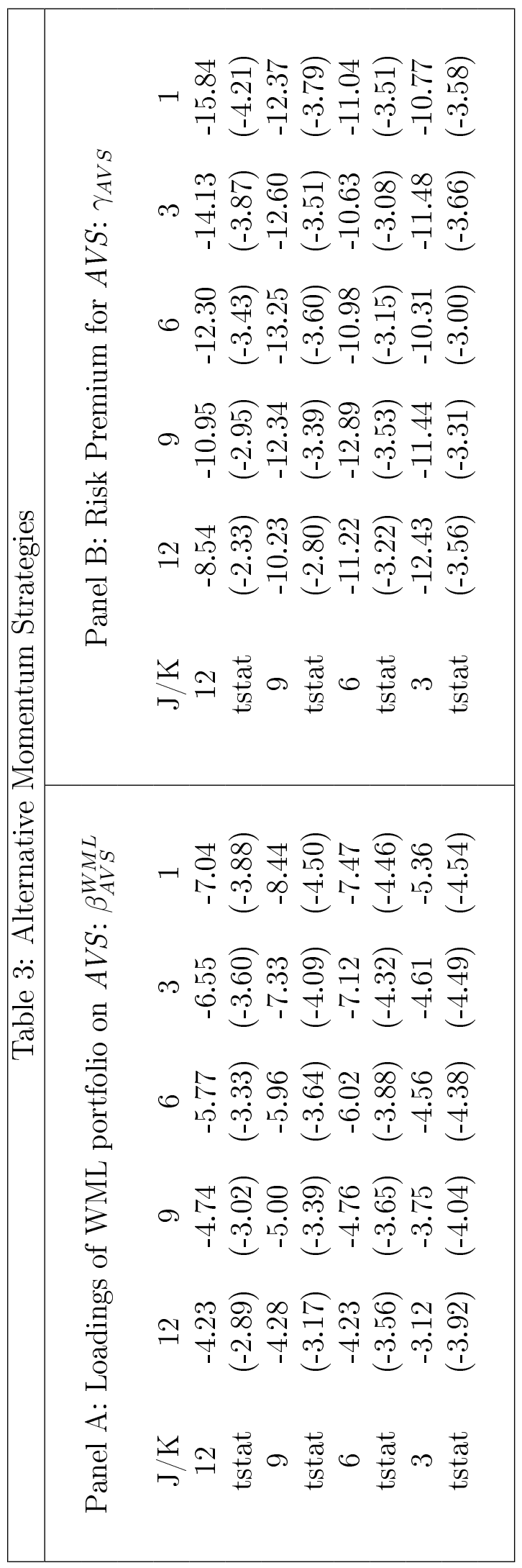




\section{Table 4: Fama-MacBeth (1973) Method: Four Factor Model (Rm-Rf, SMB, HML, AVS)}

This table presents the output of Fama-MacBeth (1973) cross-sectional regressions. The multifactor model is an unconditional model that uses excess market return $r_{m}-r_{f}, S M B, H M L$ and aggregate volatility shock $(A V S)$ as factors. $A V S$ is the weighted innovation of an EGARCH $(1,1)$ model for the monthly series of $r_{m}-r_{f}$. The test assets are 10 equal-weighted momentum $(6 / 1 / 6)$ portfolios, 12 equal-weighted industry portfolios and three factors of Fama and French (1993). Panel A presents evidence for the entire sample period January 1941-December 2009 and the other panels report subperiod evidence. For each cross-sectional regression, I report the estimates of risk premia $\gamma$ (in \% form), Fama-MacBeth (1973) and Shanken (1992) t-statistics, the OLS $R^{2}$ and the GLS $R^{2}$. In addition, each panel displays time-series regression outputs, e.g., AVS loadings, their robust standard errors (both statistics are in $\%$ form) and the p-values from the following Wald tests that I perform after a GMM-HAC system estimation. $H_{0}: \beta_{A V S}^{m o m}=0$ tests the joint significance of the AVS loadings of momentum portfolios. $H_{0}$ : $\beta_{A V S}^{L}=\beta_{A V S}^{W}$ tests the null that losers and winners have equal AVS loadings. 


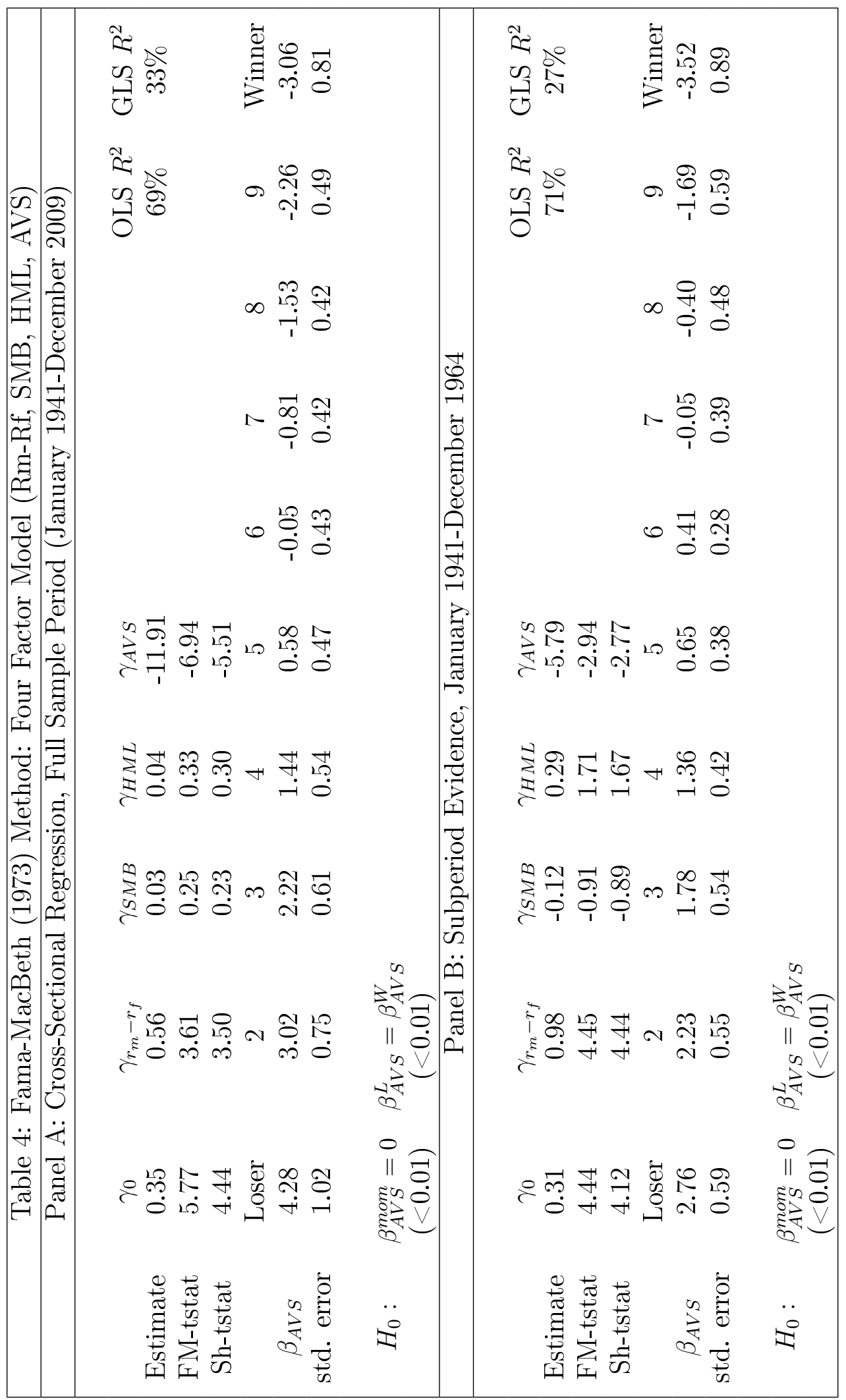









\section{Table 5: Time Series Evolution of Aggregate Volatility Shock (AVS) Loadings}

This table presents the relative aggregate volatility risk of 10 equal-weighted momentum portfolios in each of the 24 preformation months and 24 postformation months. For each portfolio formation month $t$, I compute excess returns of each portfolio in month $(t+m)$, where $m=-23,-22, \ldots, 0,1, \ldots, 24$. Each portfolio is reformed monthly from April 1955 to December 2007. I also skip one month between the end of the ranking period and the start of the holding period. Each portfolio has (a) a time series of 633 ( $t$-23) returns covering May 1953-January 2006 period, (b) a time series of $633(t)$ returns covering April 1955-December 2007 period, (c) a time series of $633(t+24)$ returns covering April 1957-December 2009 period, (d) and a total of 48 such time series, one for every preranking or postranking month $m$ in event time expressed in relation to the portfolio formation month $t$. For each preranking or postranking month $m$, I report the aggregate volatility shock loadings $\beta_{A V S}$ of 10 momentum portfolios, the AVS loading of $W M L$ portfolio, the average return on $W M L$ portfolio (and its robust t-statistic) as well as the p-values (in parentheses) from the following Wald tests that are run after a GMM-HAC system estimation. $H_{0}: \beta_{A V S}^{m o m}=$ same ("same" in table) tests the null that all 10 momentum portfolios have the same aggregate volatility risk. $H_{0}: \beta_{A V S}^{L}=\beta_{A V S}^{W}$ ("L $=\mathrm{W}$ " in table) tests the null that loser portfolio and winner portfolio have equal loadings. AVS loadings and the average returns on $W M L$ portfolios are reported in percentage form. 


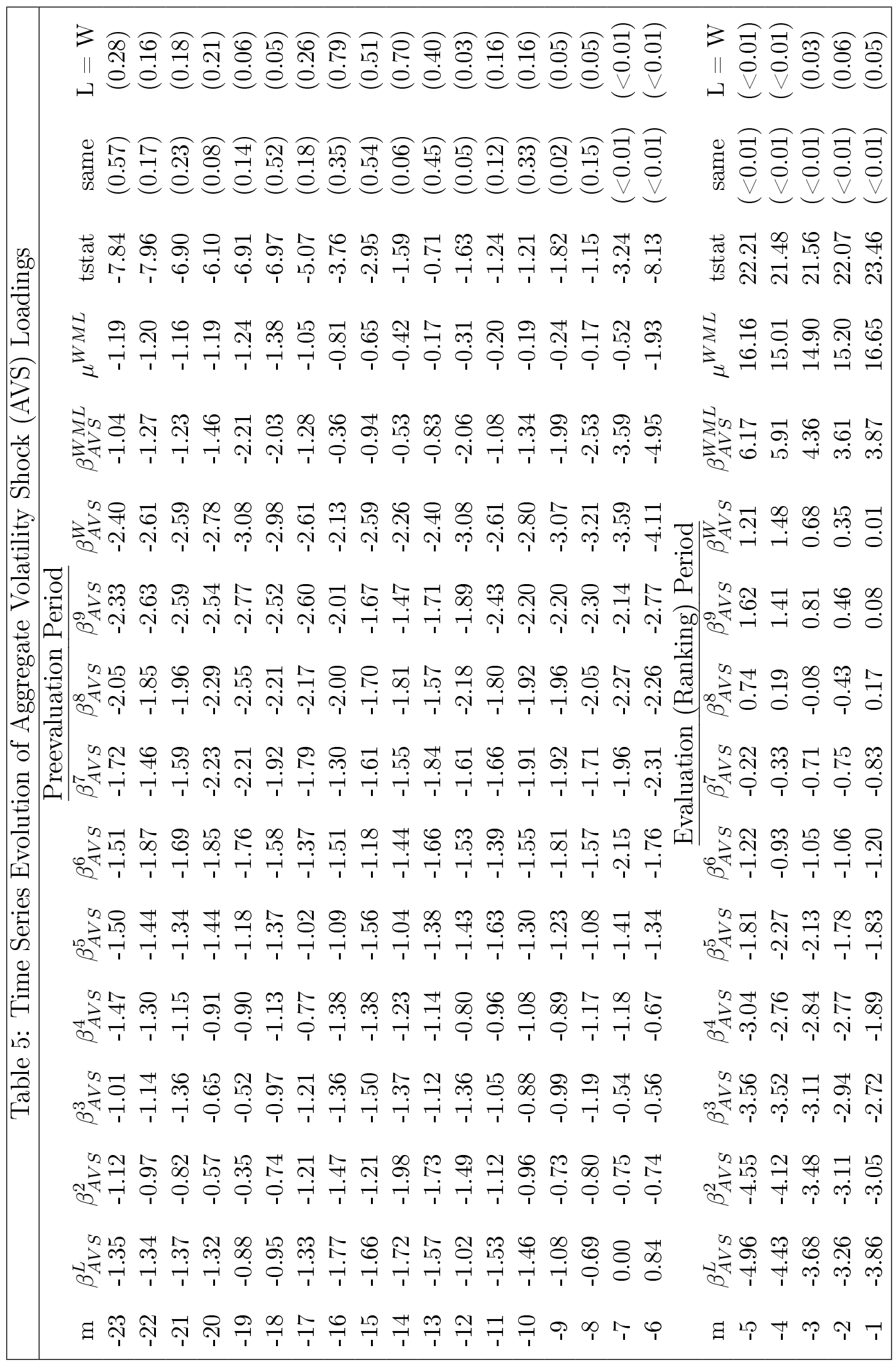









\section{Table 6: Event Time Analysis: Market States and Holding Period Statistics}

At the end of each portfolio formation month $t$ from April 1955 to December 2007, I undertake two tasks. First, I assign each stock in CRSP database whose price is greater than $\$ 1$ into an equal-weighted momentum decile according to its prior return from $t-6$ to $t-1$. Second, I define market states by looking at the market performance over the past two years. A nonnegative excess market return $(R m-R f \geq 0)$ from $t-24$ to $t-1$ composes the up market state and a negative excess market return $(R m-R f<0)$ forms the down market state. For every postformation month $m=1, \ldots, 24$, I run the regression $R_{i}-R_{f}=\beta_{0}^{i}+\beta_{1}^{i} \cdot R_{m}-R_{f}+\beta_{2}^{i}$. $u^{D I V}+\beta_{3}^{i} \cdot u^{D E F}+\beta_{2}^{i} \cdot u^{T E R M}+\beta_{3}^{i} \cdot u^{R F}+\beta_{A V S}^{i, u p} \cdot D^{u p} \cdot A V S+\beta_{A V S}^{i, d o w n} \cdot\left(1-D^{u p}\right) \cdot A V S$ , where $D^{u p}$ is a dummy variable that equals to one if the market performance from $t$-24 to $t$ - 1 is nonnegative. Panel A (Panel B) displays up (down) market statistics. In each panel I report the $A V S$ loadings of losers $\beta_{A V S}^{L \text {, state }}$ and winners $\beta_{A V S}^{W, \text { state }}$ as well as the return on the $W M L$ portfolio for each holding month $m$. All three statistics are shown in percentage form. In addition, each panel presents the p-values (in parentheses) from the following Wald tests that are performed after a GMM-HAC system estimation. $H_{0}: \beta_{A V S}^{m o m}=$ same tests the null hypothesis that all 10 momentum portfolios have the same aggregate volatility risk in a given state. $H_{0}: \beta_{A V S}^{L, \text { state }}=\beta_{A V S}^{W, \text { state }}$ tests the null that loser portfolio and winner portfolio have equal loadings. $N$ is the number of observations associated with each market state. 







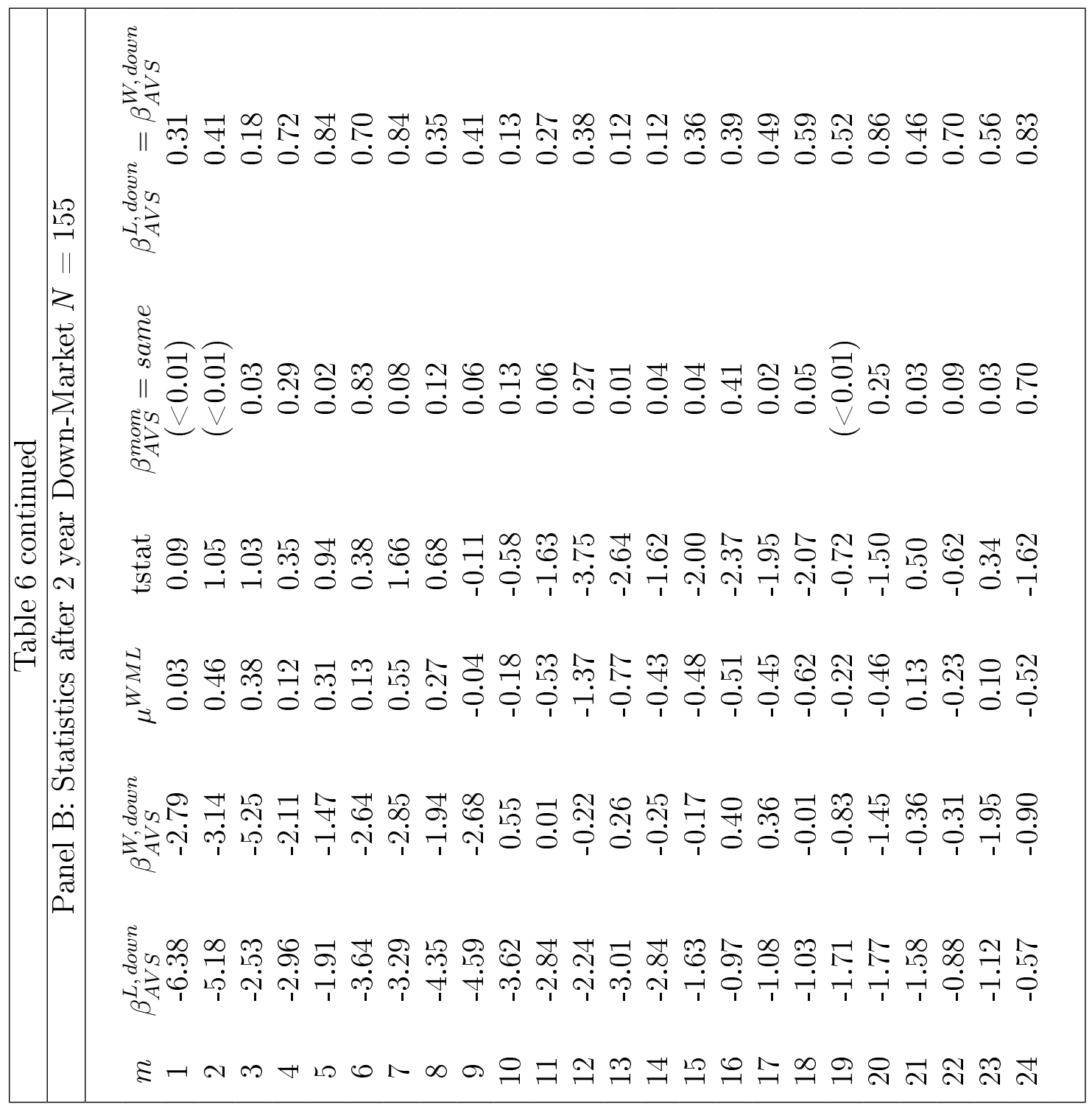




\section{Table 7: The Impact of Volatility Shock on Abnormal Investment Growth}

This table shows the results of the following event study: Investors form three momentum portfolios at the end of each quarter $t$ and the aggregate volatility shock (AVS) hits the economy in quarter $t+1$. For every stock allocated into a momentum portfolio, I compute its abnormal investment growth (AIG) rate which measures the change in annual investment activity after the appearance of AVS relative to the average investment activity before the evaluation period. AIG is the dependent variable in pooled OLS regression: The regressors are the constant term, a quarterly proxy for AVS, the ratio of market equity to book equity $\left(\frac{M}{B}\right)$ and a proxy for lagged cash flow. I interact all regressors with momentum dummy variables $1_{i}$ which equals to 1 if the stock belongs to momentum portfolio $i \in\{$ Loser, Middle, Winner $\}$ as of portfolio formation quarter t. Each panel displays the statistics for one momentum portfolio. I report the regression coefficients (in \% form), Newey-West t-statistics and the mean value of AIG at portfolio level. Losers are bottom $30 \%$ stocks that have the lowest prior returns, winners include top $30 \%$ performers, and the remaining stocks belong to the middle portfolio. Stocks with a minimum price of $\$ 5$ and nonmissing accounting data are allocated into these portfolios. The sample runs from 1984Q1 to 2009Q4. 


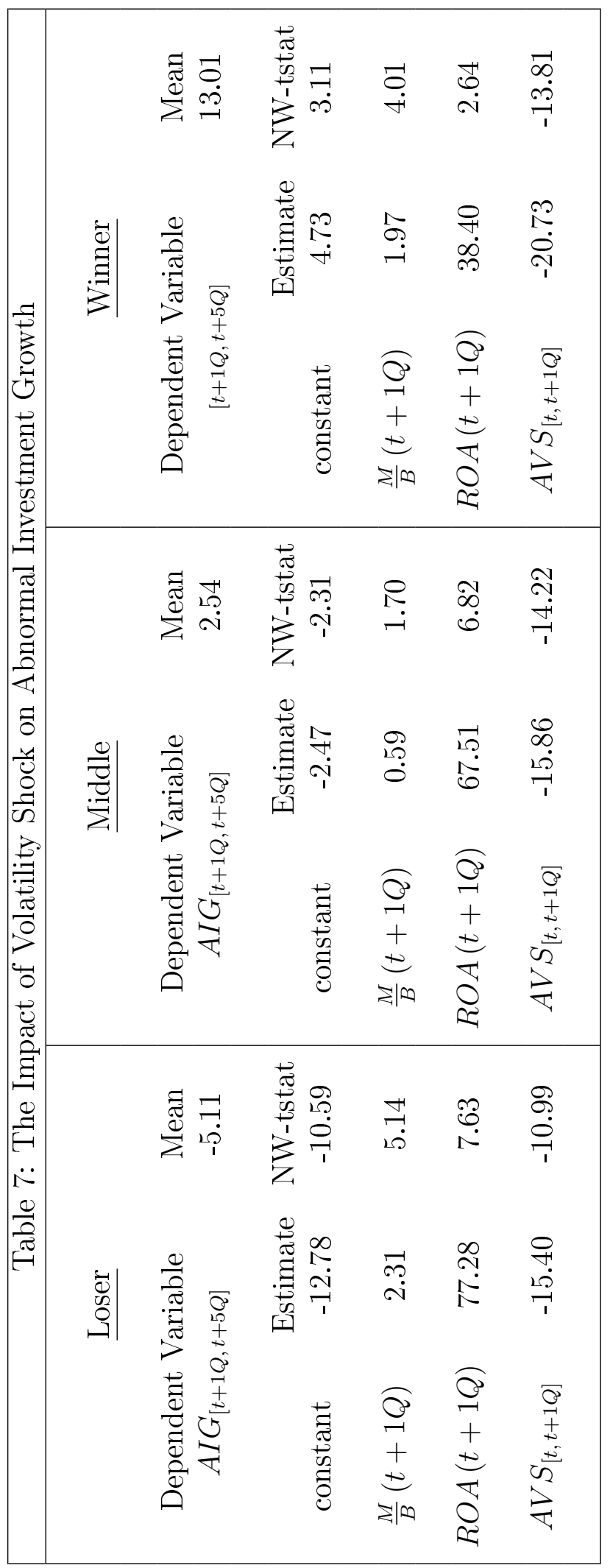




\section{Table 8: The Impact of Investment on Subsequent Returns}

At the end of each quarter t from 1984Q2 to 2008Q3, stocks with a minimum price of $\$ 5$ are allocated to momentum portfolios according to their prior returns from month t-6 to month t-1: $r_{(t-6, t-1)}$. Losers include bottom $30 \%$ stocks that have the lowest prior returns and winners include top $30 \%$ stocks with the highest returns. For each stock with nonmissing accounting and stock return data I compute annual capital expenditure starting one quarter before portfolio formation (t-1Q) and ending in quarter 3 after formation $(\mathrm{t}+3 \mathrm{Q})$ and scale it by total assets as of quarter $(\mathrm{t}-1 \mathrm{Q})$. I use this ratio $\left(i n v_{[t-1 Q, t+3 Q]}\right)$ as my investment proxy in Fama-MacBeth (1973) regressions to predict quarterly returns one year after portfolio formation: $r_{(t+4 Q, t+5 Q)}$. The one quarter gap between the dependent variable (excess stock returns) and investment-to-asset ratio ensures that the latter accounting variable is in the information set of the econometrician. $r_{(t-6, t-1)}$ is also used as a control variable in cross-sectional regressions. The fourth regression displays the average slopes for investment-to-asset ratios associated with each momentum portfolio. $1_{i}$ is a dummy variable that equals to 1 if the stock belongs to momentum portfolio $i \in\{$ Loser, Middle, Winner $\}$. All average slopes are shown in percentage form. For each portfolio $i$ average investment-to-asset ratios $\overline{i n v_{[t-1 Q, t+3 Q]}}$ are also reported in percentage form. WML denotes the difference in average ratios. The Newey-West t-statistic of this difference is reported in parenthesis. 







\section{Table 9: Conditional CAPM}

This table documents the output of conditional market regression. The conditioning variables are a constant term, dividend yield, default premium, term premium and in the risk-free rate. I define four states of the economy in the manner of Petkova and Zhang (2005) by sorting on the expected market risk premium, which I estimate by using the same conditioning variables. State "peak" refers to the lowest $10 \%$ of the observations for the premium; state "expansion" refers to below average premium; state "recession" refers to premia that are above the mean and below the highest $10 \%$ of the observations; and state "trough" refers to the highest $10 \%$ of the observations for the market risk premium. Panel A shows how conditional betas vary over the business cycle for momentum stocks. UMD is the momentum factor of Ken French. Up (Down) portfolio refers to winners (losers). I report the standard errors of the difference between the conditional betas in "peak" and "trough." Panel B presents the alpha estimate from conditional market regression. The sample spans the period May 1953-December 2009. 


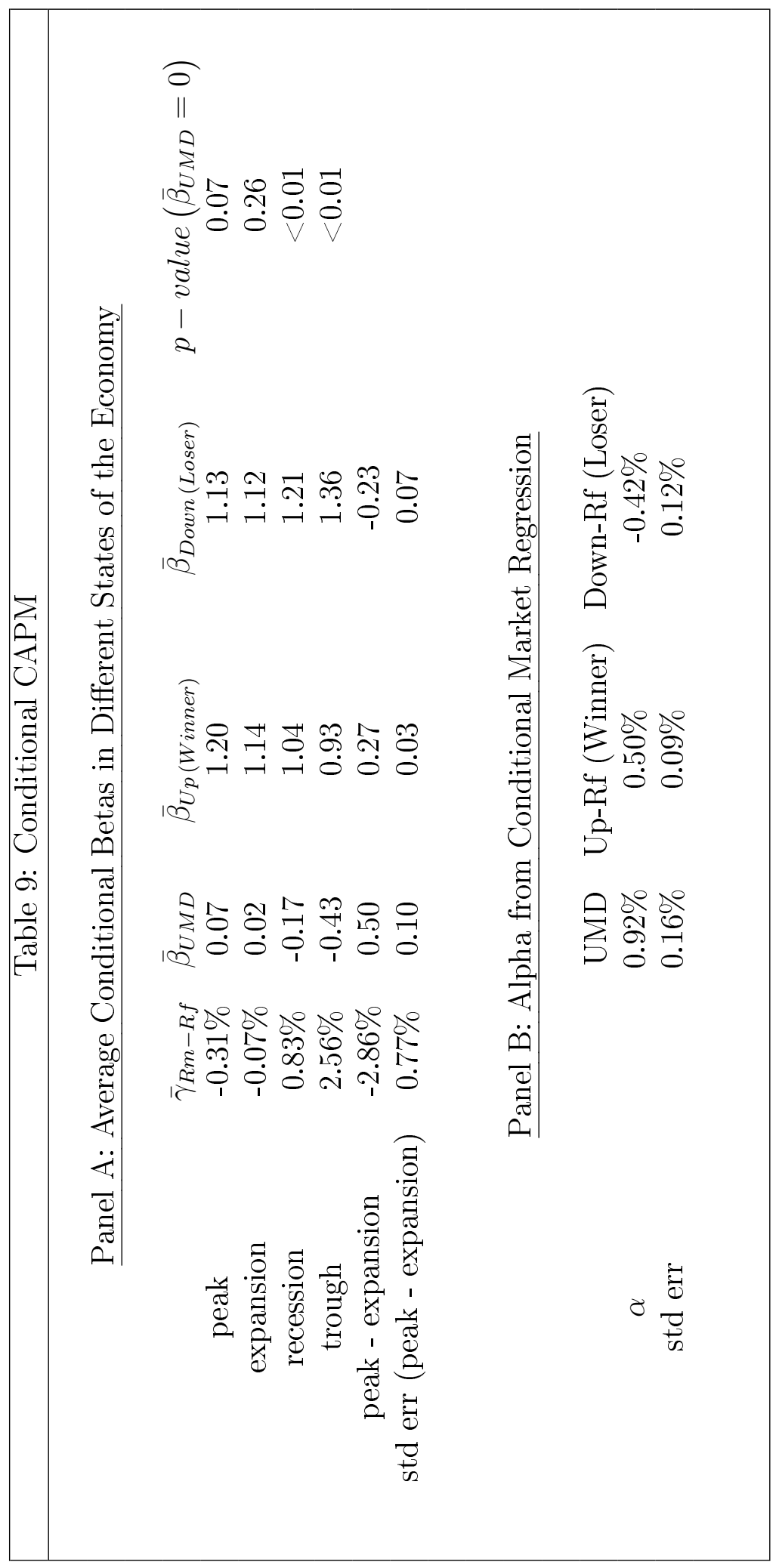




\section{Table 10: Fama-MacBeth (1973) Method with Conditional Momentum Strategies}

This table presents the AVS loadings of conditional momentum portfolios. In Panel A, the test assets are 25 equal-weighted size/momentum (6/1/6) portfolios. At the end of each month, all stocks in the CRSP database are sorted first with respect to their market capitalization and distributed into five bins. Then within each size quintile, the stocks are sorted with respect to their prior returns and allocated into five momentum portfolios. After I form these conditional momentum portfolios, I regress them on ICAPM factors and report the AVS loadings $\beta_{A V S}$. In Panel, I repeat the same exercise with 25 age/momentum portfolios. Age is the time period that has passed from the first appearance of the stock in CRSP database to portfolio formation month. Each panel also displays the p-values from the following Wald tests that are performed after a GMM-HAC system estimation. $H_{0}: \beta_{A V S}^{25}=$ same tests the joint significance of $25 \times 1$ vector of loadings. $H_{0}: \beta_{A V S}^{S W}=\beta_{A V S}^{B W}\left(H_{0}: \beta_{A V S}^{Y W}=\beta_{A V S}^{M W}\right)$ tests the null that the Small (Young) Winner portfolio and the Big (Mature) Winner portfolio have equal exposure to innovation in aggregate volatility. The sample spans the period May 1953-December 2009. 







\section{Table 11: ICAPM with VIX Innovations}

This table presents the sensitivities of momentum portfolios to volatility shock derived from VIX term structure. The multifactor model is an unconditional model based on ICAPM. The factors are excess market return, innovations in predictive variables, and a proxy for volatility shock. The first proxy is monthly changes in VIX with one-month horizon, and the loadings are reported in Panel A. The sample covers the period January 1986-December 2009. The second proxy $\varepsilon_{V I X}^{A V S}$ is the residual from the regression of twelve month VIX on short term market volatility proxies and autoregressive terms. Panel B shows the regression output, and Panel $\mathrm{C}$ shows the loadings of momentum portfolios to this innovation $\beta_{A V I X}$. The sample runs from January 1997 to December 2009. I also report the p-values from Wald tests that are performed after a GMM-HAC system estimation. $H_{0}$ : $\beta_{\text {proxy }}^{\text {mom }}=$ same tests the null that the sensitivities of momentum portfolios to the volatility shock proxy are all equal. $H_{0}: \beta_{\text {proxy }}^{L}=\beta_{\text {proxy }}^{W}$ tests the null hypothesis that the loser portfolio and the winner portfolio have equal exposure to aggregate volatility news. 


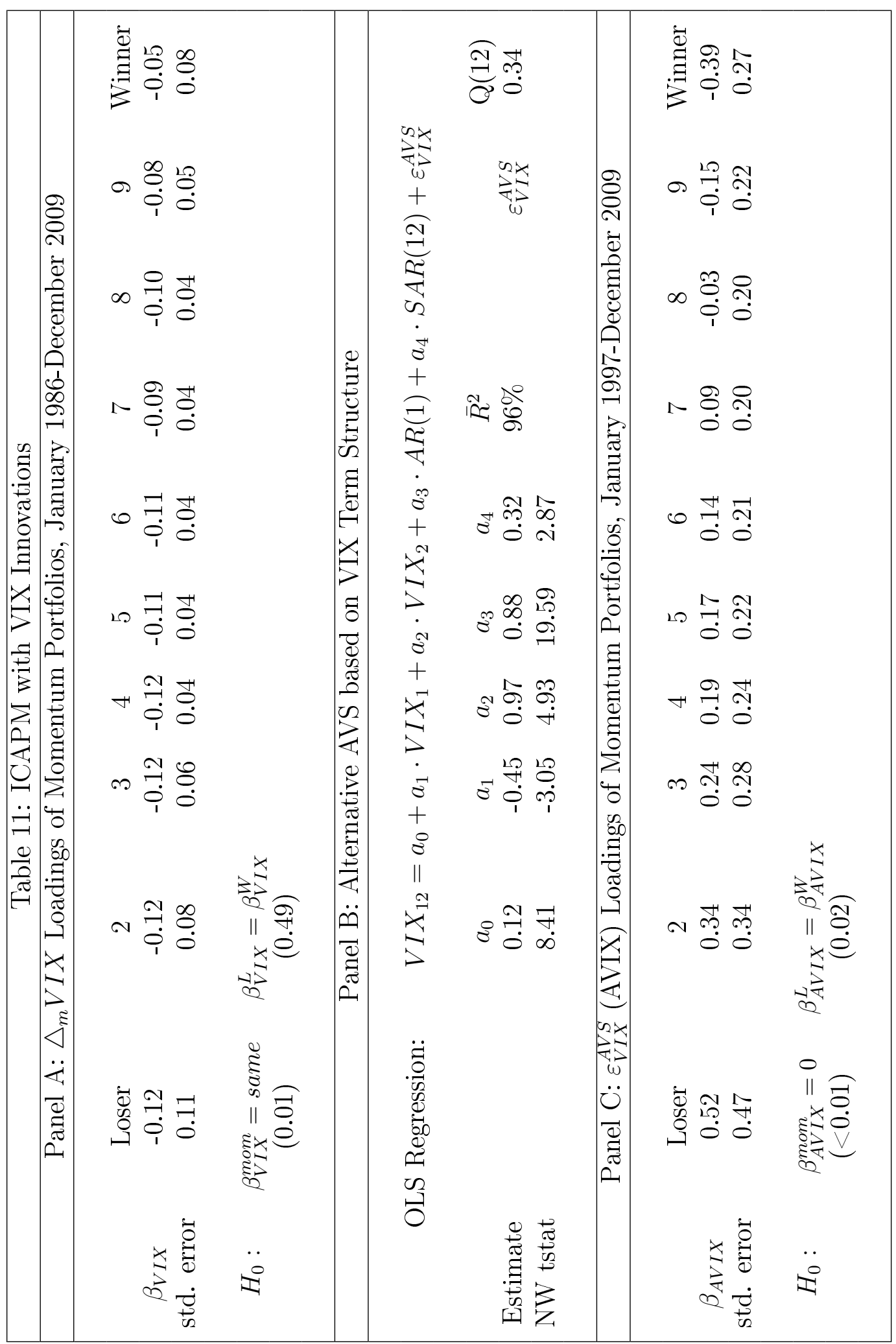


Figure 1: Aggregate Volatility Shock

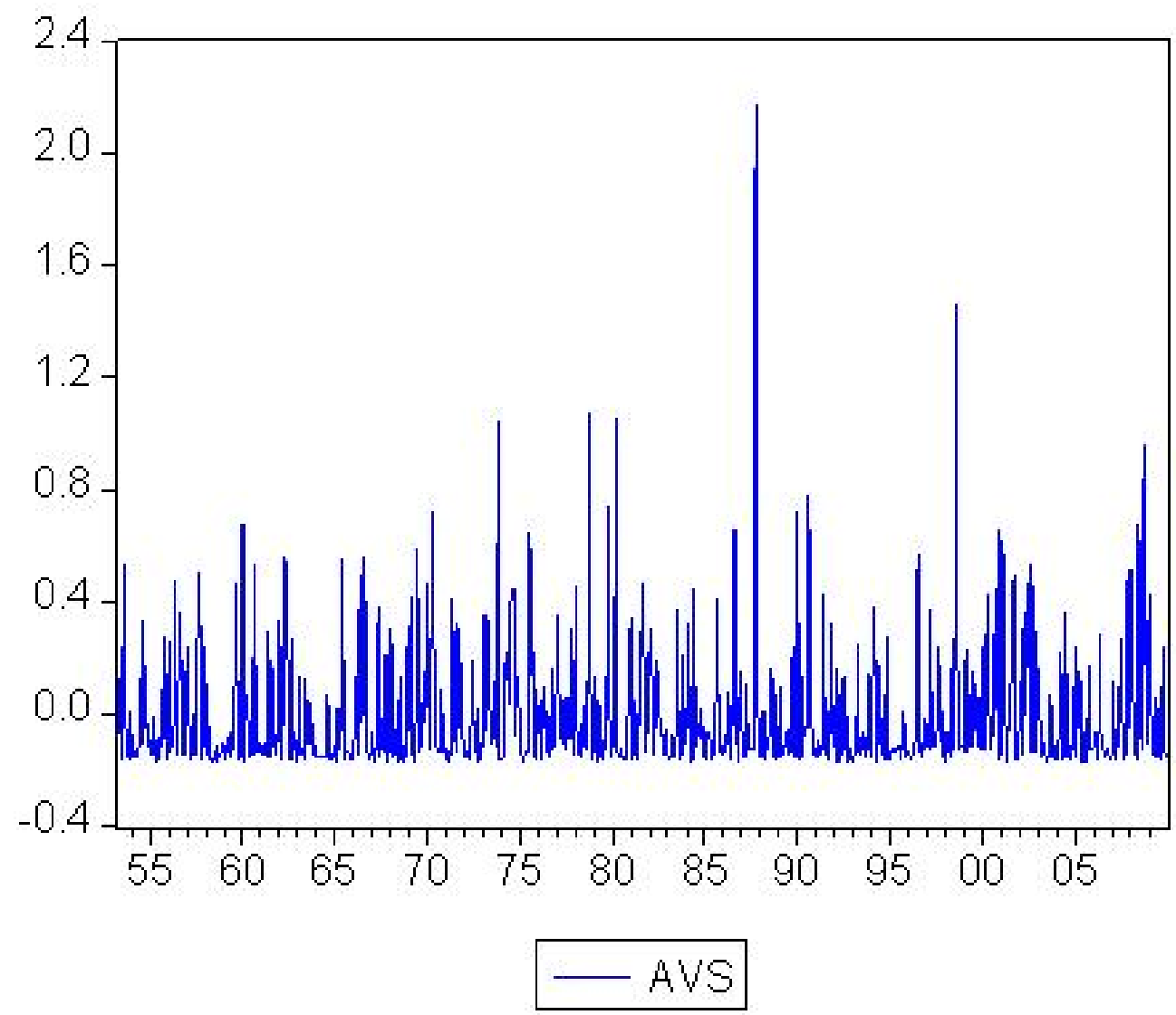

Figure 1: This figure plots the aggregate volatility shock over the full sample period May 1953-December 2009. The shock is the weighted innovation $g\left(\frac{\varepsilon_{t}}{\sigma_{t}}\right)=$ $\theta \cdot \frac{\varepsilon_{t}}{\sigma_{t}}+\gamma \cdot\left(\left|\frac{\varepsilon_{t}}{\sigma_{t}}\right|-\sqrt{\frac{2}{\pi}}\right)$ derived from an EGARCH $(1,1)$ model for monthly market excess returns. Section 2.2.2 shows that the revision in expectations about future market volatilities is positively related to this shock; hence, this shock is used as aggregate volatility risk factor throughout the paper. 
Figure 2: AVS Loadings from Event Time Regressions - Full Sample

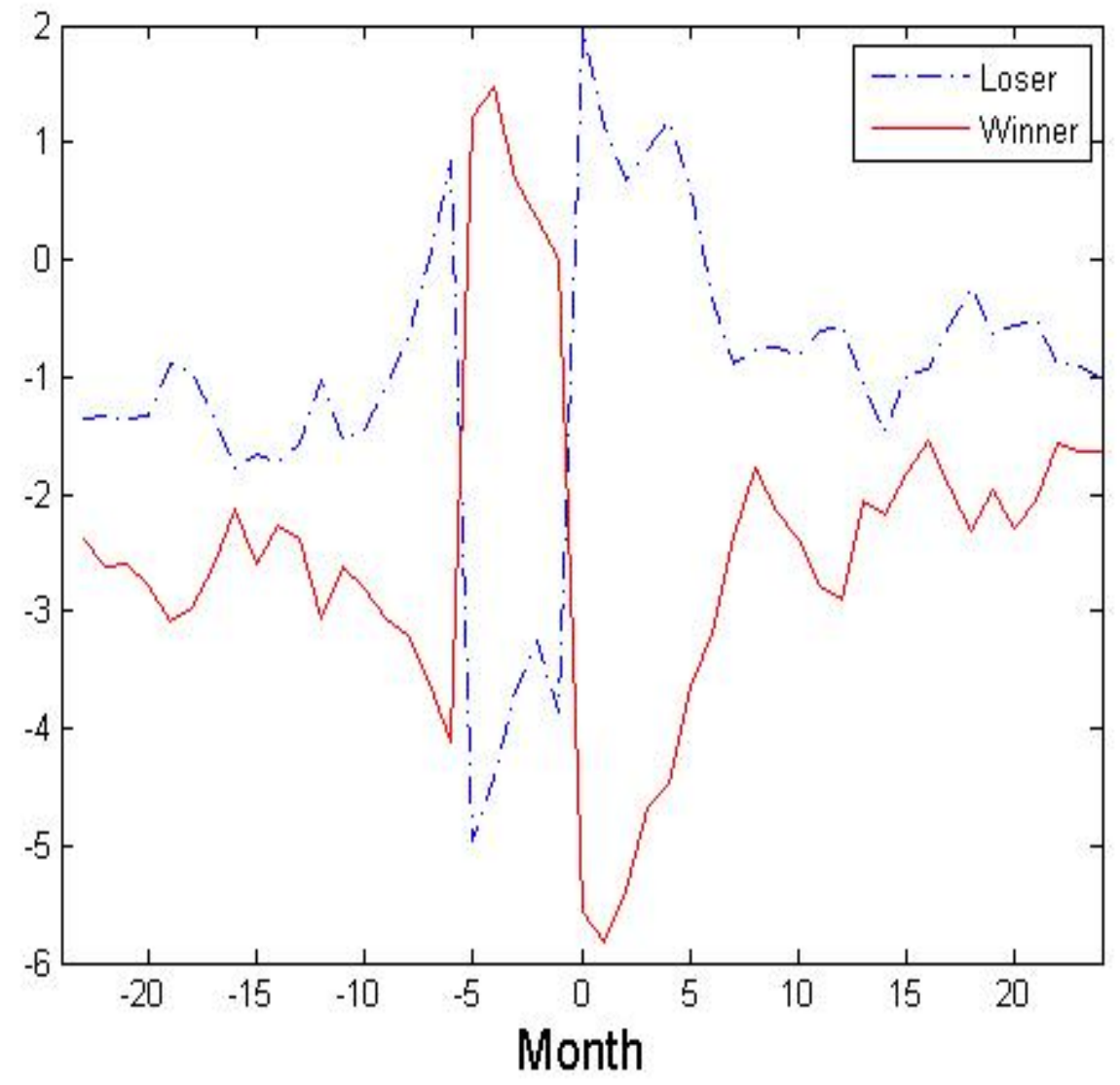

Figure 2: This figure plots the aggregate volatility shock $(A V S)$ loadings of the winner portfolio (red straight line) and the loser portfolio (blue dashed line) in event time. For every portfolio formation month $t$, I compute equallyweighted monthly excess return of each portfolio in month $(t+m)$, where $m=$ $-23,-22, \ldots, 0,1, \ldots, 24$. The portfolios are formed monthly from April 1955 to December 2007. I also skip one month between the end of the ranking period and the start of the holding period. Each portfolio has (a) a time series of 633 $(t-23)$ returns covering May 1953-January 2006 period, (b) a time series of 633 ( $t$ ) returns covering April 1955-December 2007 period, (c) a time series of 633 $(t+24)$ returns covering April 1957-December 2009 period, (d) and a total of 48 
such time series, one for every preranking or postranking month $m$ in event time expressed in relation to the portfolio formation month $t$. For each month $m$ in event time, I regress excess returns of momentum portfolios on market excess return, unorthogonalized innovations in predictive variables and the innovation in aggregate volatility. The $A V S$ loadings of the winner portfolio and those of the loser portfolio are shown in percentage form. 
Figure 3: AVS Loadings from Event Time Regressions - Subperiod Evidence

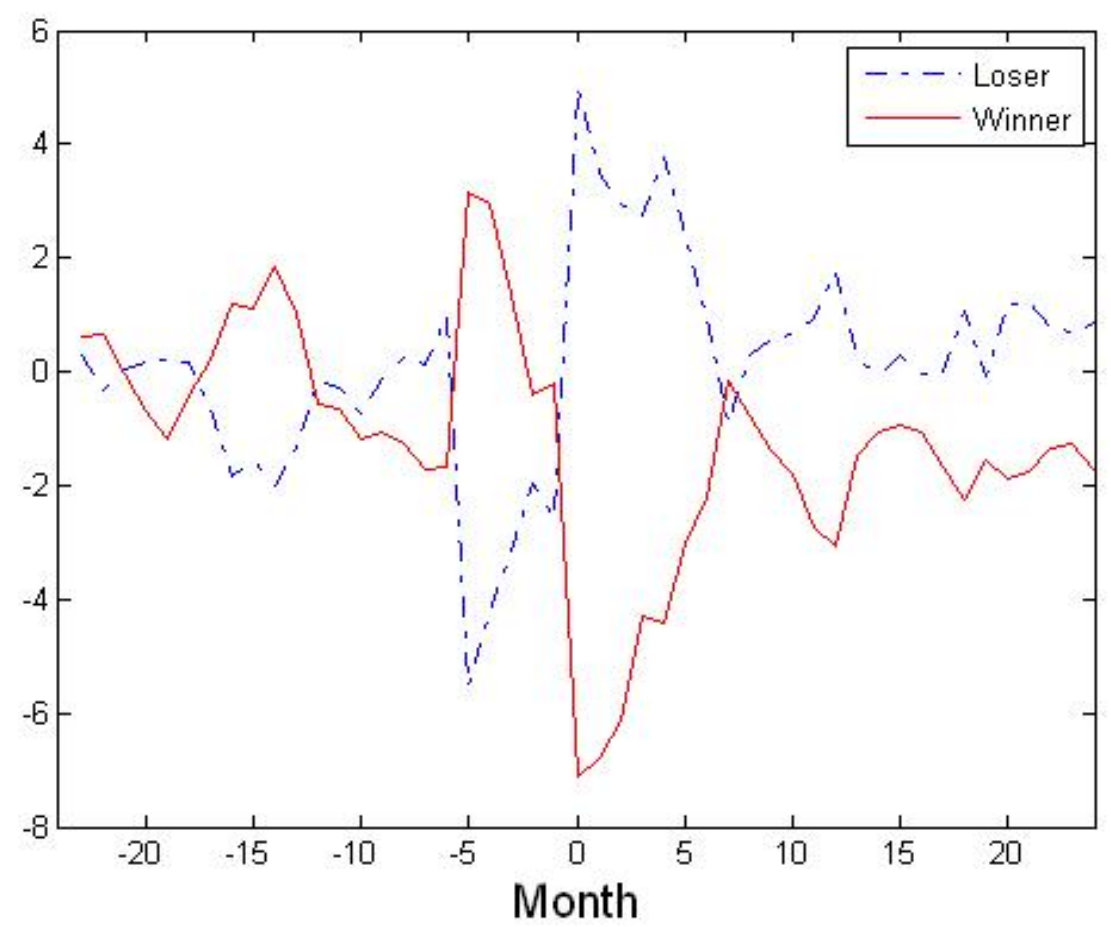

Figure 3a: This figure plots the aggregate volatility shock $(A V S)$ loadings of the winner portfolio (red straight line) and the loser portfolio (blue dashed line) in event time. For every portfolio formation month $t$, I compute equallyweighted monthly excess return of each portfolio in month $(t+m)$, where $m=$ $-23,-22, \ldots, 0,1, \ldots, 24$. The portfolios are formed monthly from April 1955 to December 1981. I also skip one month between the end of the ranking period and the start of the holding period. Each portfolio has (a) a time series of 321 ( $t$-23) returns covering May 1953-January 1980 period, (b) a time series of 321 ( $t$ ) returns covering April 1955-December 1981 period, (c) a time series of 321 $(t+24)$ returns covering April 1957-December 1983 period, (d) and a total of 48 such time series, one for every preranking or postranking month $m$ in event time expressed in relation to the portfolio formation month $t$. For each month $m$ in 
event time, I regress excess returns of momentum portfolios on market excess return, unorthogonalized innovations in predictive variables and the innovation in aggregate volatility. The $A V S$ loadings of the winner portfolio and those of the loser portfolio are shown in percentage form. 
Figure 3 continued



Figure 3b: This figure plots the aggregate volatility shock (AVS) loadings of the winner portfolio (red straight line) and the loser portfolio (blue dashed line) in event time. For every portfolio formation month $t$, I compute equallyweighted monthly excess return of each portfolio in month $(t+m)$, where $m=$ $-23,-22, \ldots, 0,1, \ldots, 24$. The portfolios are formed monthly from January 1982 to December 2007. I also skip one month between the end of the ranking period and the start of the holding period. Each portfolio has (a) a time series of $312(t-23)$ returns covering February 1980 to January 2006 period, (b) a time series of $312(t)$ returns covering January 1982 to December 2007 period, (c) a time series of 312 $(t+24)$ returns covering January 1984 to December 2009 period, (d) and a total of 48 such time series, one for every preranking or postranking month $m$ in event time expressed in relation to the portfolio formation month $t$. For each month $m$ 
in event time, I regress excess returns of momentum portfolios on market excess return, unorthogonalized innovations in predictive variables and the innovation in aggregate volatility. The $A V S$ loadings of the winner portfolio and those of the loser portfolio are shown in percentage form. 
Figure 4: Event-Time Analysis: Two Alternative Specifications Panel A: One Factor Model (AVS Loadings)

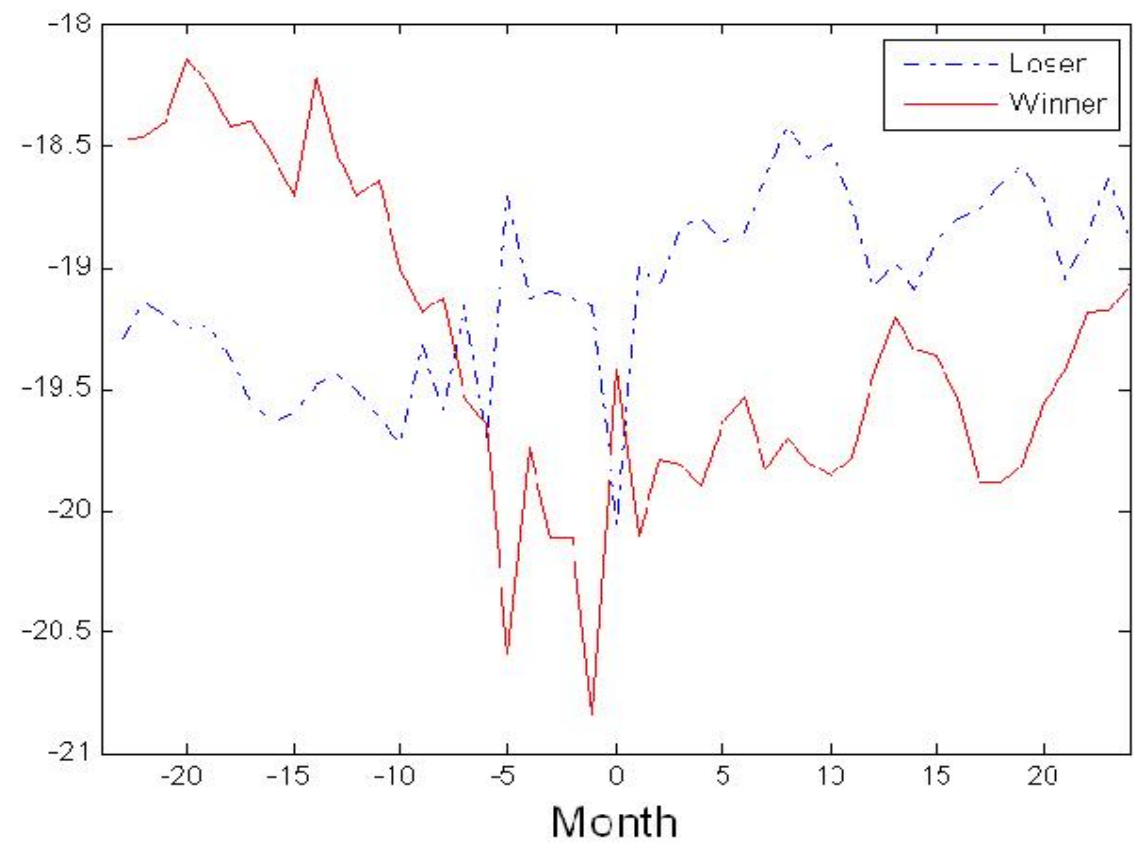

Panel B: Two Factor Model (Rm-Rf Loadings)




Figure 4 continued

Panel C: Two Factor Model (AVS Loadings)

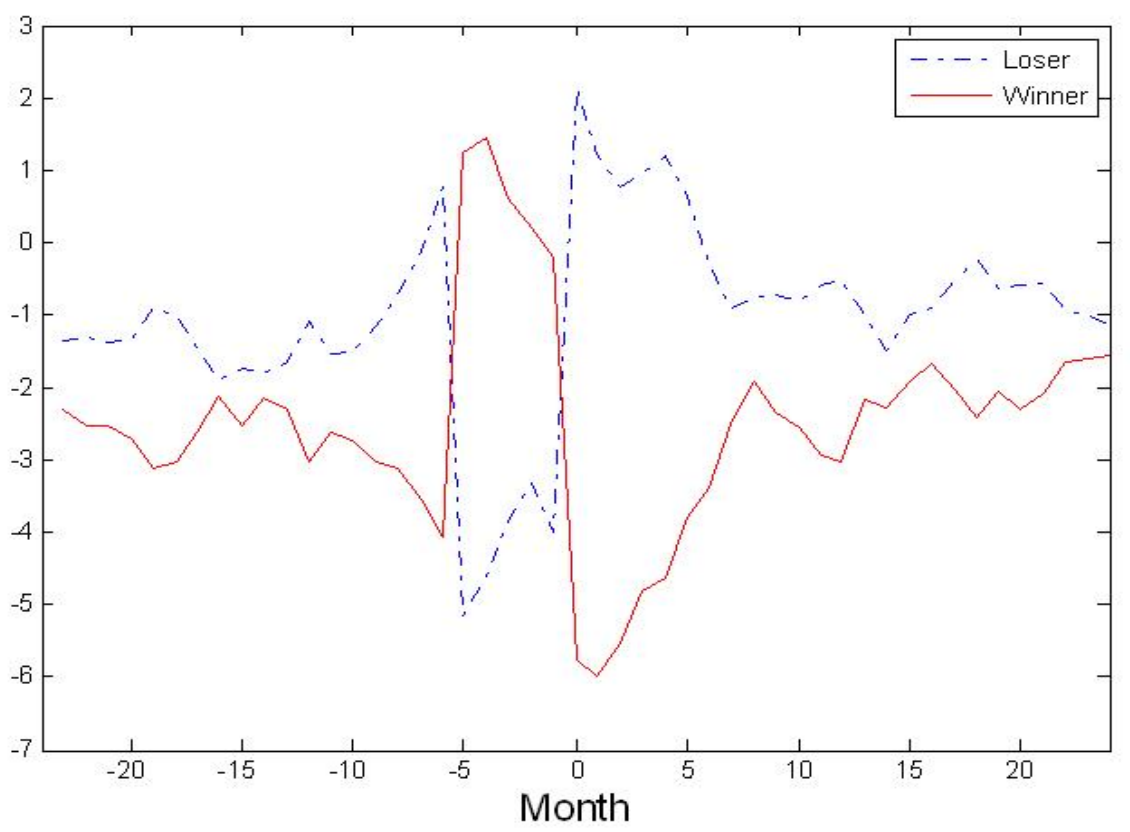

Figure 4: This figure plots the event time loadings of the winner portfolio (red straight line) and the loser portfolio (blue dashed line) for two alternative empirical specifications. The first empirical specification is a single factor model where the factor is aggregate volatility shock (AVS). The second empirical model is a two factor model where the factors are market excess return (Rm-Rf) and AVS. For every portfolio formation month $t$, I compute equally-weighted monthly excess return of each portfolio in month $(t+m)$, where $m=-23,-22, \ldots, 0,1, \ldots, 24$. The portfolios are formed monthly from April 1954 to December 2007. I also skip one month between the end of the ranking period and the start of the holding period. Each portfolio has (a) a time series of $633(t-23)$ returns covering May 1953-January 2006 period, (b) a time series of $633(t)$ returns covering April 1955-December 2007 period, (c) a time series of $633(t+24)$ returns covering April 
1957-December 2009 period, (d) and a total of 48 such time series, one for every preranking or postranking month $m$ in event time expressed in relation to the portfolio formation month $t$. First, for each month $m$ in event time I regress excess returns of momentum portfolios on AVS and report the loadings of the winners and losers in Panel A. Next, I repeat event-time regressions with the two factor model. Panel B displays loadings on market excess return and panel $\mathrm{C}$ shows AVS coefficients. The AVS loadings are shown in percentage form. 


\section{Appendix A}

By construction, in event months -5 through -1 losers (winners) have negative (positive) cumulative returns; however, this pattern does not necessarily imply that they lose (win) in every month of the ranking period. For example, the loser portfolio can contain a stock that has a negative return in month -5 and a positive return in the following month due to the short-run reversal anomaly. Hence, it seems worthwhile to examine how the prices of momentum stocks move on average during the ranking period.

First, for every momentum stock in a given portfolio formation month, I compute the number of ranking period months with a negative return. Then I average this number across all stocks within the same portfolio. Next, I repeat the same procedure in other portfolio formation months in order to obtain a time series at portfolio level. In Panel A of table A1 I report the mean of this time series for each portfolio $i=$ Loser, $2, \ldots, 9$, Winner. I find that an average loser (winner) stock has negative returns in 3.3 (1.3) months of the 5 month ranking period. This evidence supports the previous argument.

Jegadeesh and Titman (2001) show that losers are on average small stocks and Jegadeesh (1990) find that one month negative autocorrelation in stock returns is more significant among small stocks. In addition, in untabulated regressions I find that SMB explains a significant portion of the time series variation in short-run reversal portfolio returns. Therefore, I pick the four factor model for time series regressions that I run in event months -5 through -1 . The factors are Rm-Rf, SMB, HML and AVS.

During the ranking period losers (winners) have the lowest (highest) returns and this cross-sectional return dispersion happens in both up and down market 
states. Here I define the up (down) market state as the month when the market excess return is nonnegative (negative). The four factor model proposed in this study relies on the restriction that the market betas of momentum portfolios are the same in both market states, and the regression model aims to minimize the sum of squared residuals subject to this constraint. On the other hand, in up(down-) market states winners (losers) covary with the market; therefore, one can argue that removing the restriction above can provide a better fit for the regression model over the evaluation period. Next, I provide evidence for the latter argument; in addition, I show that AVS loadings of momentum portfolios become normal when momentum portfolios are allowed to have an up-market beta and a down-market beta.

Specifically, I estimate two regression models over the evaluation period. First, I run the four-factor model $(R m-R f, S M B, H M L, A V S)$ proposed in this paper and report excess market return loadings. Second, I adopt DeBondt and Thaler's (1987) method and estimate up-market and down-market betas. According to this method, I change the empirical specification by substituting two variables for market excess return. $(R m-R f \geq 0)$ is the product of the market excess return with the dummy variable $D^{U p}$ which equals to one if market excess return is nonnegative and to zero otherwise. $(R m-R f<0)$ is the product of the market excess return with $\left(1-D^{U p}\right)$. After running the multiple regressions in event time, I document the coefficients on these two new variables. The coefficient on the former variable is called up-market beta and that on the latter variable is down-market beta. I also perform two important Wald tests. $H_{0}: \beta_{\text {state }}^{L}=\beta_{\text {state }}^{W}$ tests the null that winners and losers have equal market beta in a given market state. $H_{0}: \beta_{U p}^{i}=\beta_{\text {Down }}^{i}$ tests whether the $i^{\text {th }}$ momentum portfolio's sensitivity to market excess return changes from one state to another. 
Table A1 presents the results. Panel B reports the market beta estimates from the four factor model regression in event months $m=-5, \ldots,-1$. Winners have higher market betas than do losers, and market betas increase monotonically as I move from the loser portfolio to the winner portfolio. The cross-sectional dispersion of loadings are in line with that of average returns. Panel $\mathrm{C}$ reports up- and down market betas and AVS loadings from the second regression. Most of the momentum portfolios have different up- and down-market betas over the evaluation period. For example, winners (losers) have high (low) up-market betas and low (high) down market betas. Moreover, I can reject the null hypotheses that winners (losers) have the same beta in both market states. Applying DeBondt and Thaler's (1987) method does not worsen the goodness of fit; on the contrary, for the loser portfolio there is a $2 \%$ gain in adjusted $R^{2}$ from this procedure. More important, once betas are allowed to vary with the market, AVS loadings become normal. Winners load negatively on AVS just as they do during the preevaluation months -12 through -6 and during the first year after portfolio formation. I also repeat the same analysis with ICAPM factors. AVS loadings from the empirical specification that includes an up-market variable $(R m-R f \geq 0)$, a down market variable $(R m-R f<0)$ and ICAPM innovations are qualitatively similar to the AVS loadings presented in panel $\mathrm{C}$ of table A1, e.g., winners have negative AVS loadings in months -5 through -1 . Here I present the results of the four-factor model because SMB plays an important role over the ranking period. 


\section{Table A1: Time Series Evolution of Loadings on Rm-Rf and AVS}

This table displays two features of momentum portfolios over the evaluation period (months -5 through -1). Panel A reports how many months within the evaluation period a momentum stock has negative returns. This number is averaged first across stocks that are allocated into a specific momentum portfolio in a given portfolio formation month. This procedure is repeated for every month from December 1942 to December 2007 to obtain a time series at portfolio level. Panel A shows the mean of this time series for each momentum portfolio $i=$ Loser, 2 , ..., 9, Winner. Panels B and C display the event-time factor loadings of 10 momentum portfolios. In Panel B, I use the four factor model ( $R m-R f, S M B, H M L$, $A V S)$ and report the loadings on market excess return. In Panel C, I change the specification by replacing the market excess return with two variables. (Rm-Rf $\geq$ 0 ) is the product of the market excess return with the dummy variable $D^{U p}$ which equals to 1 if market excess return is nonnegative and to 0 otherwise. $(R m-R f<0)$ is the product of the market excess return with $\left(1-D^{U p}\right)$. After running the multiple regressions in event time, I document the Up-market beta $\beta_{U p}^{i}$, Down-market beta $\beta_{\text {Down }}^{i}$, and the AVS loading (in $\%$ form) of the $i^{\text {th }}$ momentum portfolio. For each evaluation month $m=-5, \ldots-1$, I report the p-values (in parentheses) from the following Wald tests that are run after a GMM-HAC system estimation. $H_{0}: \beta_{\text {factor }}^{\text {mom }}=$ same ("same" in table) tests the null that all momentum portfolios have the same exposure to the factor of interest. $H_{0}: \beta_{\text {factor }}^{L}=\beta_{\text {factor }}^{W}$ (" $\mathrm{L}$ $=\mathrm{W}^{\prime \prime}$ in table) tests the null that losers and winners have equal loadings. $H_{0}$ : $\beta_{U p}^{i}=\beta_{\text {Down }}^{i}$ tests whether the $i^{\text {th }}$ momentum portfolio has the same market beta in both states. For each portfolio $i$, I also compute the goodness-of fit gain $\left(\triangle \bar{R}^{2}\right)$ from choosing the empirical specification of Panel C over the model of Panel B. 







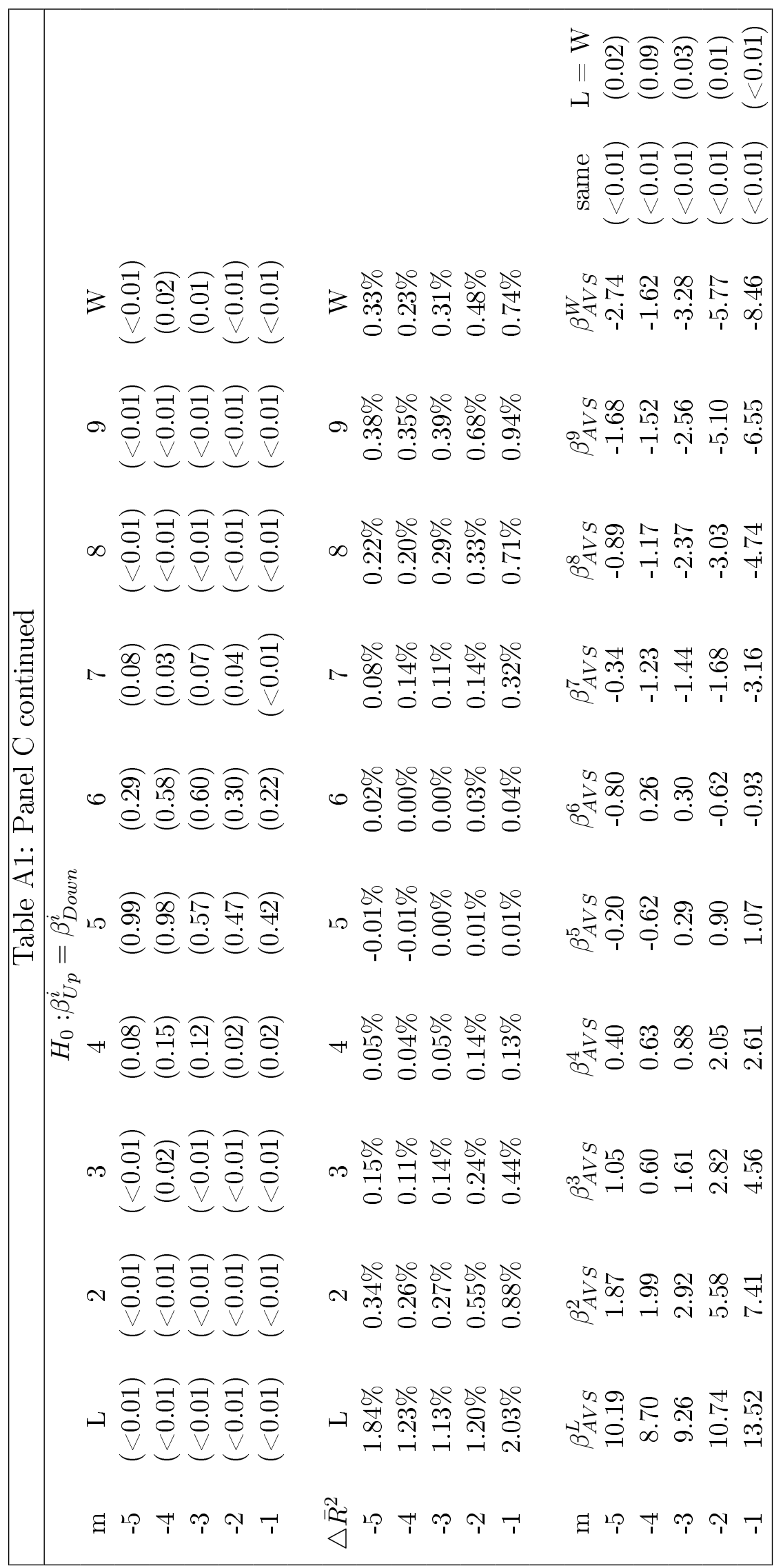

